\title{
Tourism Education, Curriculum Spaces, Knowledge Production, and Disciplinary Pluralism
}

\author{
Ramesh Raj Kunwar *
}

Knowledge is only one of the roads, only one side of that coin. The other road, the other side of the coin, is that of understanding.

(Max-Neef, 2005, p.15; in Hollinshead \& Ivanova, 2013, p. 54)

\begin{abstract}
In course of designing the courses, the present author in the phase of curriculum coordination, consulted various research papers and books based on the theoretical models of tourism and hospitality education. The review of those works not only have broadened the mind of curriculum designer but also has given knowledge education on various fields of tourism education. It is strongly believed that tourism education will become the backbone and impetus for making tourism as an institution and industry stronger. One of the most important aspects of studying tourism is disciplinarian approach. The sources of knowledge production are based on monodiscipline, multidiscipline, interdiscipline, transdiscipline, extradiscipline, postdiscipline, antidiscipline, metadiscipline and nomadology also coined as disciplinary pluralism or plurydisciplines that have created a disciplinary dilemma. The curriculum should be designed on the basis of praxis and phronesis (Aristotalian thought based on application and theory), Tourism Education Future Initiative's ( TEFI ) model, John Tribe's (1997) model ( TF1 and TF2), Echtner's (1995) three pronged approach, Mayaka and Akama's (2007 \& 2015) curriculum space model and Koh's (1994) marketing approach and others. All the above mentioned theoretical models and approaches
\end{abstract}

\footnotetext{
* Prof. Dr. Ramesh Raj Kunwar is the author of eight books on tourism and anthropology. He teaches tourism and hospitality at various universities and colleges as visiting professor. He is the former Dean of Faculty of Humanities and Social Sciences, Tribhuvan University. Previously he is also former Dean of Nepalese Military Academy, Kharipati, Bhaktapur. He is also the Chief Editor of Journal of Tourism and Hospitality Education. He is also one of the Editorial Board Members of Journal on Tourism and Sustainble Development. Currently he has been designated as an Academic Advisor to Nepal Mountain Academy, Ministry of Culture, Tourism and Civil Aviation, Nepal. Email: kunwar.dr@gmail.com
} 
will help in thinking of and thinking for tourism and hospitality. Simultaneously, it will also help for knowing, seeing, doing and being in the field of education in relation with tourism, hospitality and events (THE). But in this study, only tourism education has been prioritized.

Tourism academic world has debated and advocated regarding different approaches, concepts, models, theories and paradigms developed by different scholars of tourism and hospitality.

The scientific and reliable arguments have been occurred in different timelines, centralized on tourism education, research, knowledge, phenomena, normative and existential knowledge, successful intelligence, learning, life-long learning, collaboration, professionalism competences, scholarship, disciplines, academic territory, academic tribe, field, forcefield, studies, knowledge production, philosophic practitioner, curriculum space, management, social sciences, disciplinary pluralism, liberal and vocational balance in the field of tourism and hospitality subjects that have become the force for understanding tourism education in a better way.

Keywords: tourism education, theories, knowledge production, philosophic practitioner education, disciplinary pluralism,

\section{Introduction}

Before starting to design the courses on tourism, hospitality and event management studies, some questions hit in the mind of curriculum coordinator i.e. What is tourism? What is tourism education? What subjects should be incorporated? Is it discipline or a field? What is the benefit of tourism education? Who will get benefit? What kind of theories are found in tourism education? What kind of knowledge has been produced from pluri-disciplines in the field of tourism education?

Today human beings live in a complex world and they assume that this complexity is a result of modern technology.It is also not true that the world is socially complex. Social complexity has been the case from the time the first human community was established on the face of this earth. It is the social complexity compounded by the technology complexity that makes the job of the manager of today truly challenging (Kane, 1986, p.149).

The global importance of tourism has generated the need for answers to problems such as economic development, social impact, stakeholder conflicts, environmental degradation and politics control. These questions all seek 'the truth' but the orientation is different. The business world wants to know 'who, what, when, and where' for that is 
their 'bottom line'. Their approach is essentially quantitative, and statistically oriented for forecasting.

Tourism and hospitality have also been identified as potential tools to address the United Nations millennium development goals (United Nations World Tourism Organization, 2010; in Dredge et al., 2011, p. 2164), which include poverty alleviation, tolerance, social responsibility, employment and environmental conservation (Higgins-Desbiolles, 2006, 2011; in Dredge et al., 2011, pp. 2164-2165). Tourism changes landscapes, patterns of social and economic development, and its impacts are uneven and cumulative. This peculiarity places 'a special burden.... On education because as economic prosperity and consumer satisfaction are generated from the development of tourism, changes to people and place also occur' (Tribe, 2002a 2002 b, p.339). Externalities produced by an industry that is principally profit-driven need to be managed. The challenge for T\&H education is to produce graduates who can rise to the challenge of providing leadership for and stewardship over tourism (Sheldon et al., 2008; Tribe, 2002a). Herein lies the challenge of conceptualizing a $\mathrm{T} \& \mathrm{H}$ management curriculum space that is focused enough to support a variety of pathways through the space to produce adaptable human capital for industry and society more generally (Dredge et al., 2011, pp. 2164-2165).

Among the many intellectual treasures left to the modern world by the ancient Greeks is the notion of paideia. In contrast to the term banausos, which means technical, skill building education paideia refers to the education of whole persons toward the pursuit of achieving the full development of what it means to be human (Fotopoulos, 2005; in Caton, 2015, p. 43). Today, as Cornel West (2009: 22; in Caton, 2015: 43) conveys, it means something more like a 'deep education' that connects us 'to profound issues in serious ways'. As he goes on to explain, 'paideia' instructs us to turn our attention from the superficial to the substantial, from the frivolous to the serious.

Valene L. Smith (in Phillimore \& Goodson, 2004) in her foreword writes, "The phenomenal growth of tourism in the past five decades has dramatically changed global lifestyle to include tourism, and the impetus for still greater growth is rooted in globalization and the expanding economies of Asia".

Global climate change and shifts in the utilization of natural resources ( including fossil- based energy sources, water, land, biodiversity, food resources) will continue affecting tourism patterns and consumer behavior ( Gossling, Hall, Peeters \& Scott, 2010; UNEP, 2002; in Fuchs, Fredman \& Jonades, 2015, p.63).

\section{The Phenomenon of Tourism}

'Phenomenon' means a state or process known through the senses, in other words that can be 'experienced'. Incidentally the alternative, more popular definition of 
phenomenon is that of a remarkable occurrence which can be a synonym for 'special event'(Gaze,2007,p.9)

Tourism is essentially an activity engaged in by human beings and the minimum necessary features that need to exist for it to be said to have occurred include the act of travel from one place to another, a particular set of motives for engaging in that travel (excluding commuting for work), and the engagement in activity at the destination.

A standard definition of tourism that is often used today is that of the United Nations World Tourism Organization : Tourism comprises the activities of persons travelling to and staying in places outside their usual environment for not more than one consecutive year for leisure, business and other purposes" (UNWTO),1995,p.10; in Fuchs et al.,2015, p.68). Meanwhile, several academics have sought to refine definitions of tourism for the purposes of research. Jafari and Ritchie (1981), for example, argued long ago that a working definition is essential in order to "identify the disciplinary boundaries of tourism and its building blocks".

Mathieson and Wall (1982) encompass these points in their succinct definition of tourism as: the temporary movement to destinations outside the normal home and workplace, the activities undertaken during the stay, and the facilities created to cater for the needs of tourists (p.1). Such a definition locates tourism as the sum of a number of sub activities, mainly travel, hospitality, and recreation.

It is now possible to map out the interrelationships between tourism as a phenomenon and the study of tourism. Popper's (1975; in Tribe, 1997, pp. 640-642) distinction between three worlds provides a useful framework for distinguishing between tourism as a phenomenon and as a study. The three worlds that Popper proposes are the external world (world I), human consciousness (world II), and the world of objective knowledge (world III). Tourism as a phenomenon is that external world (world I) where humans go about the business of being tourists. It is whatever humans decide to do within the fairly wide definition of the term which is large, messy, complex, and dynamic.

What is the meaning of tourism? Tourism does not begin with the act of touring, but with the construction of a worldview that renders the world 'tourable'... [ ] Tourism discourses are sets of expressions, words, and behaviours that describe places and peoples, and turn sites into easily consumable attractions (Salazar, 2006,p.326-327 ; in Wintersteiner \&Wohlmuther, 2013,p.35). Tourism, understood in this way is a social invention (not only one, but a very powerful one) to deal with the many desires of people of the modern industrialized world. But this is not a one dimensional thing. Tourism is "an arena in which many players interact and negotiate the construction of culture to different ends" (Salazar ,2006, p.329). Basically tourism can be considered a ' machine of happiness', as Pravu Majumdar puts it (Mazumdar, 2011,p.15; in 
Winstersteiner \& Wohlmuther, 2013, p .35). Thus, the cultural 'value' of tourism is one of 'travelling to happiness' (Winstersteiner \& Wohlmuther,2013,p.35).

Tourism and hospitality have been described as hallmark activities of the postmodern world: they are activities that are 'worldmaking' in that they have a creative and transformative role in the making of people and places and in the production of meanings, values and understandings about the past, present and future (Hollinshead, 2009; Urry, 2003; in Dredge et al., 2012, p. 2160). In other words, where well managed within an integrated and sustainable approach, T\&H can give meaning to places and people, add value to cultural and environmental resources, and promote peace and understanding. They can increase cultural awareness and social and cultural tolerance; address poverty, empower communities and contribute to improving economic and social well-being (e.g., Higgins-Desboilles, 2006, 2008; Sharpley, 2009; United Nations World Tourism Organization, 2010; in Dredge et al., 2012, p. 2160). Conversely, where T\&H are less well managed, or the focus is simply as a tool for economic growth and development, a range of impacts and issues can result which are well documented and extend well beyond the economic bottom line.

Globally, 238,277,000 jobs are in the tourism industry (World Travel \& Tourism Council, 2008). This equates to $8.5 \%$ of total employment or 1 job in every 11.9 individuals. $9 \%$ of global Gross domestic product and $11 \%$ of export earnings can be attributed to tourism expenditure- the later put at $£ 1502$ billion (WTTC, 2008). Social theorists, such as Evans, Campbell, and Stonehouse (2005) point to the shift from production to consumption orientated service economies in many developed countries. Here, tourism has been a key growth area since the 1980s. current employment estimates (labour market trends, 2009; Fidgeon, 2010, p.703) suggest over 2.7 million jobs are sustained by tourist activity. 1.45 million of these are directly related to tourism and a further 1.3 million indirectly (or $8.4 \%$ of the labour force). An additional 132.400 people are self-employed in tourism (Fidgeon, 2010, p. 703).

The pursuit of knowledge production in tourism has created an international market place for higher education institutions in the centres of our network- society ( Castells, 2000; in Portegies, De Haan,\& Platenkamp, 2009,p.524).

The evolving new type of tourist is characterized as quality conscious, less loyal to any particular destinations, but simultaneously empowered through new information and communication behaviors, such as web-based "comparison shopping" (Fesenmaier, Gretzel,Hwang, \& Wang, 2004 ; in Fuchs et al.,2015,p.64).

The above mentioned attributes demonstrate that there are two apposite camps regarding tourism as an industry and tourism as social force. The academic debate remains unsolved. Tourism is characterized as an industry in a great deal of publications ranging from newspapers to trade magazines to the varios kinds 
of academic publications as well as by governments and business . One academic proponent of the notion of tourism as an industry is Stephen Smith (1988; in HigginsDesbiolles, 2006). Smith offers an industrial definition of tourism which he argues will rectify the poor regard that industry leaders, government officials and economists have for tourism by allowing comparatibility with other industries ( 1988,p.182; in Higgins- Desbiolles,2006,p.1996 ). This definition what he calls a "supply side ", definition in that it shifts focus away from the tourist to the businesses who supply that those tourists: "Tourism is the aggregate of all businesses that directly provide goods or services to facilitate business, pleasure, and leisure activities away from the home environment" (1988,p.183 ).To justify his statement or definition, Smith retorts that" the tourism product is the complete travel experience" which is the complete travel, accommodation, force and attractions a tourist uses (1997,p. 149; in Higgins- Desbiolles,2006,p.1196 ) . In fact much is state when tourism development in this context requires financial investment, favorable political climates, expensive infrastructural support, subsidies and other support mechanisms .

As Sinclair and Stabler state : It is a composite product involving transport, accommodation, catering, natural resources, entertainments and other facilities and services, such as shops and banks, travel agents and tour operators . Many businesses also serve other sectors and consumer demands, thus raising the question of the extent to which suppliers of tourism. The many components of the product, supplied by a variety of businesses operating in a number of markets, create problems in analyzing tourism supply (1997,p.58; in Higgins - Desbiolles, 2006,p. 1195).

If tourism is a social force advocated by second camp is concerned, "it is important to quality the emphasis on tourism's economic contributions by highlighting it other positive impacts, which include improving individual wellbeing, fostering crosscultural understanding, facilitating learning, contributing to cultural protection, supplementing development, fostering environmental protection, promoting peace and fomenting global consciousness which contributes to the formation of global society" (Cohen \& Kennedy,2000,p.212 for the last point; WTO,1999 for the former point; in Higgins- Desbiolles, 2006,p.1197) . In the 1990s, many analysts acknowledged the power of tourism as a social force. Barnard and Spencer argue that " to ignore tourism in our account of culture contact in the $20^{\text {th }}$ century in probably as great an omission as to ignore slavery with $18^{\text {th }}$ century or colonialism in the nineteenth" ( 1998,p.2006; in Higgins- Desbiolles,2006,p.1197). Knowledge of tourism as a social force comes from the those analysts who approach tourism from sociological, psychological or anthropological perspectives ( Higgins-Desbiolles,2006,p- 1197). In this regard, McKean boldly claims: underlying tourism is a quest or an odyssey to see, and perhaps to understand, the whole inhabited earth, the oikumene. Tourism can be viewed as not an entirely banal pleasure- seeking escapism ( MacCannell,1976; 
in McKean, 1989,p.133 ) but as a profound, widely shared human desire to know "others" with the reciprocal possibility .

Go (1998) urges that "education should reflect on the question whether the present framework they have developed will ensure the successful provision of graduates for a global tourism industry in the 1990s and into the third millennium" (p.2; in Lewis \& Tribe, 2002, P. 13).

Darbellay \& Stock (2012) have distinguished three moments of the scientific approach of tourism:1. A holistic approach to tourism as a system, 2. A disciplinary fragmentation and specialization, with the emergence of tourism geography as well as tourism economics, psychology, and anthropology since 1970's and 3. A more recent interdisciplinary fertilization between 1995 and 2000 (p.448).

\section{Tourism and Research Methodology}

Research is an integral part of any academic activities. Research produces the knowledge and knowledge forms the discipline. The knowledge production and the research work always go hand in hand. This requires a lot of techniques that connect with research paradigm and philosophy. Tourism and hospitality also demands research and methodology for knowledge production. Accordingly many leading of scholars of tourism and hospitality who conducted research and have developed various theories whose purpose of developing theories for understanding tourism in better way.

The literatures of research methodology refer to, or define, research in terms of it being an activity that creates or generates new knowledge or as something that produces a contribution to the existing body of knowledge. The types of words that are commonly used in definition of what research is inside discovery, investigation, new facts, advancement of knowledge, original insights-all of which seem to suggest that undertaking research is likely to be rather daunting task and create the impression that all research is something very difficult, complicated and requires a high level of intellectual ability on the part of the researcher (Brotherton,2010,p.5). Research methods that involves the form of data collection, analysis and interpretation that researcher propose for their studies (Creswell, 2009,p.15).

A methodology refers to a broad approach that derives from the research's view of the world and/or the disciplines relevant paradigms. Empiricists generally adopt a quantitative methodology, non-empiricists a qualitative one. Again, most discussion in the hospitality literature is about methods, not methodology, although sometimes used as a synonym for quantitative research, empiricism implies for more than a methodology. Within the social sciences there are a number of alternative paradigms including one which holds that reality is entirely subjective and relativistic (Jones, 1998, p.109). 
A methodology "is a model, which entails theoretical principles as well as framework that provides guidelines about how research is done in the context of a particular paradigm" ( Sarantakos, 1998,p.32; Jennings,2009,p.672).

The Paradigms, according to Guba (1990; in Rekic 2010,p.131), are:

- positivism- with its realist (or 'naive realist'? or 'naive realism' which focuses on absolutely 'true' ) (Guba,1990,p.19; in Hollinshead, 2004, p.74; in Rekic 2010,p.131);

- $\quad$ post-positivism - with its critical realist or 'critical realism' (Rekic 2010,p.131; Guba,1990,pp.20-21; in Hollinshead,2004,p.74) and the findings are seen as probable true reflections of the 'real' world (Guba \&Lincoln,2005;in Rekic,2010,p.131);

- Critical theory- with its ideologically oriented standpoint (Guba, 1990,pp.2324; in Hollinshead, 2004,p.74); Critical theory is about deconstructing power and privileged so that an emancipatory praxis can be co-developed with communitiesand people's suffering operation(Higgins-Desbiolles,2013,p.429); and this theory has been derived from Marxist, feminist and neo-colonialism perspectives;

- Constructivism- with the dialectical outlook on the world's multiple realities (Guba, 1990,p.26;in Hollinshead,2004,p.74) a constructivist paradigm is marked by a relativist ontology and a subjectivist epistemology, that is there is a belief that realities are multiple created in the minds and that knowledge is constructed (Guba, 1990; in Rekic, 2010,p.131). Constructivism exposes the notion that "the learners' basis of meaning is found in his or her direct experience with dynamic and responsive world, and that we can only form concepts through our bodily actions".(Davis et al.,2000,p.65).

A paradigm is a particular view of the way the world operates (Kuhn, 1962;in Jennings, 2009,p.672) or "guides action"(Guba, 1990;in Jennings,2009,p.672) and is associated with four frames: ontology (the reality), epistemology (the theory of knowledge), methodology (a model or the theory of method) and axiology (values and ethics)(Jennings, 2009,p.672).

The foundational components of any tourism, hospitality and event (TH \& E) studies curriculum, namely the ontology, epistemology and axiology of TH\&E; or, in other words, how we come to understand what the fields are, what makes us accept certain matters as being truthful and constituting knowledge, and how we establish what is valuable either for its own sake, or for sometime else when we negotiate what to include in a curriculum (Edelheim,2015,p.30). 
TH\&E studies as separate academic subjects, or combined as an academic branch, can act as a field that is taught to students, an academic genre to study, and more importantly as practice aimed at enhancing the society within which TH\&E takes place (Edelheim,2015,p.30).

Goodson and Phillimore (2004: 34; in Rekić, 2010, p.131) define a paradigm as a researcher's 'basic set of beliefs that define their worldview' consisting of their ontology or the definition of reality, their epistemology or the theory of knowledge and their methodology or 'the theory of the method' (Jamal and Hollinshead, 2001: 67). In a nutshell, in order to have their studies thoroughly underpinned, researchers need to ask themselves:

1. In terms of ontology: 'What is the nature of reality and therefore what is there that can be known about it?'

2. In terms of epistemology: 'What is the nature of the relationship between the knower or would-be knower and what can be known?'

3. In terms of methodology: 'How can the inquirer (would-be knower) go about finding out whatever he or she believes can be known?' (Guba and Lincoln, 204: 21-22; in Rakić, 2010, p.131).

A particular set of onotological (i.e. realism versus relativism) and epistemological (i.e. objectivism versus subjectivism) standpoints that researchers adopt will then only inform their methodology and methods rather than strictly prescribe them (Rakić, 2010, p. 131).

By contrast 'episteme'-following Foucault (1969), Foucault (1994; in Darbellay \& Stock, 2012, p. 448)- refers to a field of formation and transformation of knowledge that cannot be reduced to an accumulation or a simple stage of different bodies of knowledge at any moment of scientific development. It takes into account the 'gap' distances, oppositions, differences, relations (Foucault, 1994, p.676;in Darbellay \&Stock,2012,p.448).

Ontology, or the study of being,creates the framework for how we, as individuals, connected in societies, make sense of the reality in which we live. The power of ontology is that it gives us the keys to unlock the way reality is understood, by taking as its object of study the actual being of things, matter, concepts, experiences, and words-essentially of everything (Edelheim, 2015, p.31).

Axiology, or the study of value or of goodness, is definitely the philosophical strain out of these three that has received least attention, even thought it is fundamentally linked to our actions in our daily lives. The value of something can be seen as having intrinsic properties, valuable in its own right, or to have extrinsic properties, valuable for the sake of something else, which in trun can have intrinsic properties (Edelheim,2015,p.31) . 
Ontologies of TH\&E refer to how we understand the existence of concepts, actions, theories, and words related to TH\&E . Taxtbook for TH\&E studies generally start with an introductory chapter that sets the scene, describes the basics of the studies, potentially define some foundational words and concepts, and thus creates the reality of TH\&E studies that our students and peers accept as an authoritative one (Edelheim,2015,p.31).

Ontology is in post- positivist texts seen as describing the nature ( Jennings, 2010) rather than reality per se- this is to highlight that socially constructed realities can exist side by side without contradicting one another (Saukko,2003;in Edelheim,2015,p.31). It is therefore important for critical theorists to ground their ontology claims in their own social reality.

Central to the argument of Heidegger's interpretation of phenomenology is the concept he named Dasein or 'being -in -the -world', which has a threefold structure: understanding- and an associated meaning; mood-that is, our mood has a bearing upon how we encounter the environment; and discourse- or the fact that something that can be formulated can be understood(Stumpf, 1994,p.506; in Edelheim,2015,p.31).

Franklin (2008;in Edelheim, 2015,p.32) suggests that TH\&E academics are doing themselves an injustice in accepting an ontology of TH\&E that puts them at the margins of society. Living in neo-liberal societies influenced by Weberian work ethics where leisure-time and pursuits are secondary in importance to work, means that TH\&E is often seen as a parenthesis in a society (Edelheim, 2015,p.32).

The term epistemology is derived from Greek word episteme meaning knowledge, which again comes from epistanai-to understand, or to know (Barnhart,1988;in Edelheim, 2015,p.32). Just as Dasein in Heidegger's terminology refers to how the individuals make sense of being and meaning through understanding, mood and discourse ( Heidegger ,1962;in Edelheim, 2015,p.32), so in epistemology lies the explanation of how knowledge is created in our minds, and accepted in our societies. What our society refers to as knowledge and truth are results of process of negotiation carried out amongst people considered experts in their fields. New discoveries, adjustments of old information, and best practices are all ideas dressed in convincing works and backed up with either data or logic to constitute a 'correct, 'true' position about a matter (Edelheim, 2015,p.32).

Belhassen and Caton (2009;in Edelheim, 2015,p.32) divide the knowledge- the epistemology- created and used in TH\&E studies into three different categories based on a linguistic framework : morphology of TH\&E; new interpretations of TH\&E ; and problem solving of practical issues of concern to TH\&E stakeholders. Their framework succinctly shows how the language we use when creating TH\&E 
knowledge is making truth claims in different ways. The first category, the morphology or lingo, refers to how terminology is introduced to TH\&E studies, often from other disciplines, and given a meaning in TH\&E literature. Examples of words and concepts that are part of the language TH\&E academics nowadays use part of their normal discourse are 'the tourist gaze" (Urry,1990;in Edelheim, 2015,p.32),or an ' experience flow'(Csikszentmihalyi, 1991; in Edelheim, 2015,p.32)-in both cases theoretical words commonly used in other fields describing specific phenomena. By applying these words in a tourist context they are introduced to the accepted language TJ\&E academics use communicate their ideas to one another.

The second category, the new interpretations of phenomena in TH\&E, highlights that different researchers perceive reality in different ways and by offering explanations that in their mind portray that reality better, new knowledge is created. The academic community internally regulates which new understandings are recognized by using peer-review process where experts in different fields evaluate whether the new interpretations reach an acceptable level. Academics also try to promote the reliability of their views of reality by, for example, creating ranking lists for publications in which new knowledge is published, citation indices, or by other means showing the impact, and thus credibility, of their finding's (Edelheim, 2015,p.32).

The third category, in Belhassen and Caton's (2009; in Edelheim, 2015,p.32) linguistic framework of TH\&E epistemology, contains knowledge that is created by describing how the application of previously accepted theories and models of ' real life' cases enhances the operating conditions of that stakeholder's practice. These practical applications are the most common ways of furthering TH\&E epistemologies. Theoreticians use words to describe how the event, business, community, nongovernmental organization, destination, or whichever stakeholder acted as the practical component, changed their practices in some way and how those new ways of acting, analyzing, or understanding practical matters led to, or at least could lead to, a better functioning environment.

Alternatively, Guba and Lincoln (2005; in Jennings,2009,p.673) outline five: positivism, post positivism, critical theory, constructivism, and participatory views. Variously in their discourse, Guba and Lincoln refer to postmodern paradigms (constructivism and postmodernist critical theory) (see in detail Rakić, 2010, p. 131).

Another paradigmatic framing drawn from tourism studies identifies three paradigms: scientific positivism, interpretive method, critical theory (Tribe, 2001,in Jennings,2009,p.673).

Tourism research ,typically takes place in the form of multi and postdisciplinary study field (Coles et al., 2006; Echtner \& Jamal , 1997; Tribe , 2006 ). In order to 
address complex issues of human affairs, scholars increasing identify themselves with learning outside of established disciplinary agendas" (Coles et al , 2006 ,p. 303), thereby effectively modularizing knowledge on new subject matters, thereby development, or methods. Examples for new area of inquiry include tourism and xenotourism, welfare shopping environmental change and complexity/ chaos theory ( Baggio , 2008, Coles , 2006 ; in Fuchs et al.,2015 ,p.69).

Social and environmental science framings emphasized tourism phenomena as complex, multimodel, multisector, multiparticipant phenomena with multiple stakeholder (human and non-human) interactions, interrelationships, and interconnetivitises. Bussiness framings in the 2000s are starting to embrace similar holistic framings (Jennings, 2009, p.676).

Towards the end of the twentieth and into the twenty-first centuries, aided by greater inclusion of social and environmental sciences into tourism research and studies, other paradigms commenced broadening and informing researching tourism studies, this paradigms include interpretive social sciences, critical theory orientation, and participatory action research (Jennings, 2009, p.676).

To reiterate, the history of tourism research and disciplinary-related inquires of tourism phenomena, described here as "tourism studies", is one that has been grounded in the hard sciences, in scientific inquiry informed by positivism and postpositivism (including that branch of postpostivism described as cultural realism). Alternative approaches, such as those informed by interpretive social sciences, critical theory orientation, and participatory action research tended to be marginalized or pushed into other disciplinary areas, where such paradigmatic approaches were accepted in order to gain voice, representation, and publication (Jennings, 2009, p.676).

An effort has been made to prepare tourism curriculum as a field that integrates theory with practice and bridge divide the between business research methods and growing social science perspective. Here it is highly focused on tourism as a business (human resource, marketing, finance and entrepreneurship) or as a social phenomenon from a multitude of perspectives (geography, economics, psychology, anthropology, law, safety and security). Although many institutions elect to consider, indeed place, tourism in business faculties or schools, some are located in social science division or schools and there in growing interest in teaching and research tourism from a social science perspective. The two sides of tourism have increasingly become polarized within the nomenclature of Tourism Management or Tourism Studies. Such aspects of tourism have often followed the predictable route whereby tourism management research is seen to be dominated by positivism and the laws of natural science, whilst tourism studies research tries to counter what it sees as a somewhat mechanistic approach, by highlighting the advantages of phenomenological methodologies 
(Franklin \& Crang, 20011; in Ritchie, Burns \& Palmer, 2005, P.3).Academically tourism business studies is being supported by the international refereed journal i.e. Tourism Management based on quantitative research whereas tourism social science research is supported by refereed journals named Annals of Tourism Research and Tourist Studies.

There are four main Journals on hospitality named Hospitality Research Journals (now called Hospitality and Tourism Research Journals), International Journal of Contemporary Hospitality Management, International Journal of Hospitality Management, and Cornell Hotel Restaurant Administration Quarterly. Among these journals, International Journal of Hospitality Management is very strong in Human resources whereas Cornell Hotel Restaurant Administration Quarterly tends to balance three disciplines of marketing human resources and accounting research (Jones,1998 p.108).

Based on the philosophy of science described by T. Kuhn (1970) in The Structure of Scientific Revolutions, tourism studies seems to be in a "pre-science" or pre-paradigmatic" phase. According to Kuhn, a pre-paradigmatic science "... characterized by total disagreement and constant debate over fundamentals... there will be almost as many theories as there are workers in the field and each theoretician will be obelized to start afresh and justify his own particular approach" (cited in Chalmer, 1982, p. 92; in Echtner \& Jamal, 1997, p.875).

Kuhn's treatise suggest that in commensurability is a barrier to the development of a distinct discipline of tourism studies... However, the disciplinary dilemma takes a different perspective when one applies R. Bernstein's (1991) philosophy of science. Using this approach, the principle problem impeding tourism's theoretical development seems not to be caused by in commensurability but by an inappropriate, dominant philosophical and methodological approach (Echtner \& Jamal, 1997, p. 877). "We seek to discover some common ground to reconcile differences through debate, conversation, and dialogue... what matters is not unanimity but discourse"(Bernstein, 1991, p.223; in Echtner \&Jamal, 1997, pp.877-878). He indicates that alternate approaches (he favors hermeneutics and praxis) will allow researcher to span across disciplines and to develop a comprehensive, deeper understandings of all human activity.

\section{Knowledge Management}

The dictionary meaning of knowledge is knowing facts, information, ideas, instruction, wisdom and learning etc. It originates from the minds of people and also acquired through different experiences, values, information, which could be evaluated and applied in known areas (Rajaram, 2008,p.137;in Kunwar,2013,p.20). Knowledge is the basis of talent training, to meet the requirements of professional 
ability, knowledge structure of tourism students should reflect the level of basic knowledge, expertise and related knowledge, the unity of theoretical knowledge and practical training, the correspondence of the knowledge content and the job requirements. Tourism practitioners need to have culture, basic knowledge, professional knowledge, the knowledge of professional theory and the practice application for the positions demand, the development knowledge of cultivating adaptation to community and innovate ability. Tourism profession is a strong professional practice, practitioners need to have strong knowledge in addition to the structure, should also have strong practical ability, observation ability, professional key capacity and skilled specialized capabilities. So that they can be more into the role quickly after coming into companies to assume their responsibilities, reduce post application stage, and become useful business professionals through business training. (Mao \& Wang, 2010,p. 88)

One aspect of real-world complexity is job complexity. Much of what we actually do at work is becoming more knowledge intensive. "Knowledge-an intangible-is a key ingredient in the success of tangible product" (Oblinger \& Verville, 1998,p.10; in Repko, 2012,p.34).

Knowledge is directly or indirectly associated with education. Education is considered as crucial for the improvement of the ability to evaluate things (Binkhorst et al, 2010,p.47). Education is deeply rooted with knowledge. Knowledge, says one thinker, is the third eye of man, which gives him insight into all affairs and teaches him how to act (Altaker, 1975,p.4;in Kunwar,2013,p.20) and evaluate the things.

Tourism and hospitality programs across the globe have followed different developmental paths and have engaged in the development of student understanding, criticality and reflexivity associated with the Philosophic Practitioner Education (PPE) in diverse ways (Lashley, 1999; Morrison \& O’Mahony, 2003; in Dredge et al., 2012, p. 2157). However, for educators in both tourism and hospitality fields, how to foster practical wisdom or prudence is a significant common challenge. Students require learning opportunities that facilitate the development of higher order knowledge, opportunities to learn and practice skills, and opportunities to apply and reflect on practical judgment.

Knowledge can be described as: (1) experience and skill acquired by a person through experience or education; (2) the theoretical or practical understanding of a subject; (3) facts and information about a field; or (4) awareness or familiarity gained by experience of a fact or situation. Knowledge comes in both explicit and tacit formats (Sheldon \& Fesenmaier, 2015, p. 158).The explicit type of knowledge is tangible whereas tacit knowledge is knowledge is intangible. Explicit knowledge is collected, stored, distributed and shared primarily as electronic or paper documents. It is simply the 
knowledge acquired through training and education. Tacit knowledge involves special productive knowledge and skill possessed by individual. It also includes cognitive skills such as belief, images, institution and mental models as well as technical skills, processes and some of consider to the aim (Zaei \& Zaei, 2014, p. 116).

The question of knowing about what one knows about tourism is an epistemological question, epistemology being that branch of philosophy which studies knowledge. Its essential concern is the analysis of the validity of a claim to know something. The epistemology of tourism thus inquiries into the character of tourism knowledge, the sources of tourism knowledge, the validity and reliability of claims of knowledge of the external world of tourism, the use of concepts, the boundaries of tourism studies, and the categorization of tourism studies as a discipline or a field (Tribe,1997, p.639). Knowledge Management (KM) was first coined by Karl Wiig in 1986, propose that the foundation of knowledge management is comprised of the way knowledge is created, used in problem solving and decision making, and manifested cognitively as well as in culture technology and procedures (Wiig, 1995 ; in Zaei \& Zaei, 2014,p.115).

In his book Post-Capitalist Society (1993), Drucker (1993; in Zaei \& Zaei, 2014, p. 116) claimed that the Western World was entering into what he denoted as the knowledge society in which the basic economic resource would be knowledge and no longer capital, natural resources or labor. Drucker emphasized that organizations have to be prepared to abandon knowledge that has become outdated andlearn to create new knowledge through: (1) continuing improvement of every activity; (2) development of new applications from its own successes; and (3) continuous innovation as an organized process. This period has the most to offer the tourism (Cooper, 2006) and hospitality industry. As the Information Age moves into the knowledge economy, knowledge has become an essential resource for developing competitive advantage based on the production, distribution and use of information.

...Knowledge management has become big business, growing explosively since Drucker drew attention to it in 1988 (Drucker, 1988;in Grant, 2011,V-VI). As Smith (2004) suggested "Knowledge management is a rapidly growing field that crosses diverse disciplines", from psychology to information systems, can be "viewed as a conceptually complex broad umbrella of issue and viewpoints" (Grant, 2011,VI). Knowledge comprises strategy, practice, method and wisdom of doing right. Knowledge management be define as the set of systematic and organizational processes incorporated to manage organizations' knowledge (Alavi \& Leidner,2001;in Rachela \& Hu,2009,pp.565). An organizations knowledge is the professional intellect, including both what and how, and the experiences, values, and beliefs of its members (Nonaka,Takeuchi \& Umemoto,1996; in Rachela \& Hu,2009,p.565). some researchers ( Nonaka \& Takeuchi,1995; Bose \& Sugumaran,2003; in Rachela \& Hu,2009,p.565) proposed knowledge management frameworks that essentially consists of the 
following three processes: (1) Acquisitions and storage _ knowledge is identified and collected from various sources of the organizations, converted into explicit form, and stored in organizational repositories ; (2) retrieval , disseminations , and use relevant knowledge is distributed to employees and subunits of the organizational where and when it is required ; and (3) evaluation and feedback _ knowledge is used and evaluated by the employees for its effectiveness, with feedback guiding further knowledge acquisition ( Rachela \& Hu ,2009, p.565). Knowledge management can not only assist decision markers in doing their jobs effectively but can also enable organizations to share and reuse different resources effectively (Rachela \& $\mathrm{Hu}, 2009$,p.564)

According to Rajaram (2008,p.139; Kunwar, 2013,p.20 , knowledge management is a systematic process of coordinating activities of acquiring, creating, storing, sharing, diffusing, developing and deploying knowledge by individuals and groups in the pursuit of growth. He further elaborates that "Knowledge is largely cognitive and highly personal, while management involves organizational processes. Knowledge management, therefore, facilitates creation of new knowledge, increases awareness and understanding” (Rajaram, 2008,p.139;in Kunwar,2013,p.20).

In light of new social dynamics generated by postmodernism (Firat \&Sholakia,2006;in Tzortzaki, Mihiotis \& Agiomirgianakis, 2011, p.326) and the rise of the experience economy, tourists have become better informed and more discerning. As a result of the "increasingly complex and diverse needs of demand", new tourism paradigms, such as experimental tourism, have began to emerge (Fayos Sola,1996,p.406;inTzortzaki et al., 2011,p.326). On the supply side of tourism, the ability of absorbing and applying market knowledge is pivotal to strategic competitiveness (Zahra \&George,2002; in Tzortzaki et al., 2011,p.326). In this way, "Knowledge is seen as the engine for evolution" (Mandell, 2008 ; in Tzorzaki et al. ,2011, p.326) which will allow for the development of a more sustainable market offering.

Researchers and practitioners have found in many organizations intangible resources (e.g., knowledge and customer relationships) are key performance drivers and create intellectual capital (IC) (Edvinsion, 2013; in Zeglat \&Zigan, 2014,p.83). Intellectual capital is often referred to as the value that is created by three types of intangible resources, that is, human capital(HC), such as knowledge, structural capital (SC), such as information and communication systems and relational capital ((RC), such as partnerships with stakeholders (Stewart, 1997; in Zeglat \&Zigan, 2014,p.83). In the hotel industry, managers need to identify and manage the key drivers of performance in their organizations (Pike, et al., 2005; in Zeglat \&Zigan, 2014,p.83). Knowledge on how to effectively manage intellectual capital is vital, in particular in industrial sectors that are service oriented and non-manufacturing, since these sectors possess more intangible resources (Bontis \& Fitz-enz,2002; in Zeglat \&Zigan, 
2014,p.83). The hotel sector is a sector and hotel organizations possess intellectual capital resulting from the knowledge and skills of employees, processes and systems, and customer relationships. Tavitiyaman et al.(2012; in Zeglat \& Zigan, 2014,p.8384) claim that hotels with strong resources can differentiate themselves from their competitors and survive in a competitive environment.

\section{Tourism Education}

The great eastern philosopher Kuan-tzu who lived in 500 B.C said "If you plan for an year plant a seed. If for ten years, plant coconut or fruit-bearing tree. If for a hundred years teach the people. When you sow a seed, you will reap a single harvest. When you teach you will reap a hundred harvests" (Rajaram, 2008,p.75). Investing in people is the basic requirement for laying a sound foundation of a steady economic growth. Countries cannot utilize their full potential without maximizing their knowledge and skills of their human capital. The concept of human capital dates back to late seventeenth century, when an economist, William Petty (1623-1687), attempted for the first time to estimate the value of population of England in 1681.

Tourism is a high need for human capital and offers a diversity of jobs in a variety of operations of varied sizes and types (Szivas et al., 2003; in Liu \& Wall, 2006,p.160).Human capital aims at reinforcing an important concept that people are the fundamental force behind every successful industry. Human capital arises out of any activity able to raise individual worker. In practice full time education is too readily taken as the principal example. For works human capital involves both direct costs in forgone earnings (Marshall, 2004, p.296).

Tourism education can be described as one of the main sub-sectors of the multifaceted tourism phenomenon and whose manifestation could impact on the whole of the tourism sector directly or indirectly. The United Nation World Tourism Organisation (UNWTO) has singled out tourism (higher) education is holding a potential to achieving a customer satisfaction and also improving the competitiveness of tourism business and regions if specific education and training guaranteed (Fayos Sola, 1997; in Maureen et al., 2008,p.191). Tourism higher education has attained formal recognition in several countries. Knowledge in the production of education.

Broadly educational theories can be classified according to two domains: the theories of learning and the theories of knowledge they profess ( Hein, 1998 ; in Hein,2006,p.345). Theories of learning can be roughly grouped along a continuum from "passive" to "active", that is, from theories, on one extreme, that consider the mind to be a passive recipient of new sensations that are absorbed, classified, and learned, to the opposite extreme that postulates that learning consists of active engagement of the mind with the external world, where in the learner gains knowledge by thinking about and acting on the external world in response to stimuli. Theories 
of knowledge are concerned with whether learning entails acquiring truths about nature or constructing knowledge, either personally or culturally, that is "true" only for those who accept it (Hein,2006,p.345).

Historically the trend of tourism education has been shifted when the international conference on "New Horizons in Tourism and Hospitality in Education, Training and Research" held in Calgary,Canada in 1991. Their first joint conference, “Tourism Teaching into the 1990's “ was held on the UK Campus in 1988.( Buergermeister, D’Amore, Jafari \& Pearce, 1992, p.139). These two conferences were the historical landmark of showing remarkable significance of tourism education on one hand and making scientification of tourism or advancement of tourism hospitality education and research including knowledge production on the other. The conference elaborated an increasingly critical appraisal of tourism education relating the structure and content of the courses. Further, the multifaceted nature of the tourism was recognised, requiring an interdisciplinary or multidisciplinary study of the subject ( Buergermeister, D’Amore, Jafari \& Pearce, 1992, p.141).

There are already more than 573 tourism education related articles published in the past 10 years. Results indicated the need for philosophical discussion about the nature of tourism education and the popularity of teaching and learning approaches as a research topic (Hsu, 2015, p.1). Recently two different seminal books entitled Tourism Education edited by Pauline J. Sheldon and Cathy H.C. Hsu (2015) and The Routledge Handbook of Tourism and Hospitality Education edited by Diana Dredge , David Airey and M.J. Gross (2015) came out in the academia. These books including other research articles published in international journals have become impetus for understanding what tourism education is and what tourism education should be.

Tourism education in Europe originates from technical training schools. This explains why tourism curricular have been dominated by a focus on industry-specific occupational skills. One can say that the traditional academic content (marketing, finance, management, and human resources as well internships are closely related to specific needs of the industry) (Ritalahti, 2015,p.137). Good employability as a success factor in higher tourism education is in the center of discourse of the tourism pedagogy. The typical model of classroom education of previous centuries was perhaps effective then, but the knowledge society requires new thinking about teaching and learning ( Ritlalahti, 2015,p.137).

Tourism education and training are imperative for securing positive effect of tourism in destination. "... a common characteristic is an orientation towards technical competence associated with achieving service quality and international standards which is also an internationally accepted goal of tourism education and training (World Tourism Organization, 1999; in Liu \& Well, 2006,p.167), 
Moreover, training as supposed to education has traditionally dominated to tourism industry in which vocationally-oriented courses played a crucial role in producing the necessary craft skills for many years (Cooper \& Shepherd, 1997; in Maureen et al., 2008,p.192). A notable distinction between education and training emanates from Zais (1976,p.317; in Maureen et al., 2008,p.192) work or curriculum in which he defines training as "a technical model directed towards specific behavioral changes" meanwhile "education is directed toward expanding ones awareness of human environment and how to cope with the environment".

As we move to a knowledge-based world where educational institutions have lost their monopoly on knowledge, it must be accepted that scholars will no longer come from the traditional institutions of higher learning. New knowledge will be created by whoever is in a position to do so and wherever it is needed and value. If current researchers do not recognise this important trend, they will find themselves forever wondering why no one seems interested in their work. Let the new millennium serve as the catalyst for the metamorphosis of hospitality into a serious scholarly pursuit (Olsen, 2003,p.104;in Kunwar,2013,p.20).

Neoliberalism is one of the most debated ideologies in both education and political economy (Apple, 2008;Maureen,2008,p.196). Margison and Considine (2000:in Maureen et al,2008,p.197) associate neo-liberalism with the adoption of a management- like approach in handling the affairs of the public sector and the unprecedented interest in achieving efficiency and better performance.Some key features of neoliberalism are 'competition', 'profitability', 'progress', 'entrepreneurship', 'individuality', 'economic rationality', and 'free' market environment. Managerialism, one of perspectives of neoliberalism, conjures up the image of universities as businesses as opposed to conventional sites of autonomous knowledge (Hoyle \& Wallace, 2005; in Maureen et al., 2008,p.198).

Tourism development puts forward higher requirement to tourism of college and universities. Tourism education is utmost is important for younger generation in this $21^{\text {st }}$ century. Education provides knowledge and knowledge provides truth and empowerment including awareness to all stakeholders.

Tourism education has a pivotal role to play in facilitating the paradigm shift from the passive to the transformative. As such the role of tourism education has to be realigned to drive the transformative agenda. Various approaches to tourism education has been proposed over the year emphasizing a vocational; liberal or combined agenda depending on the context- These approaches revolve around the four strands of higher education: student- centered approach (Cooper \& Shepherd,1997,p.35) , a workcentered approach (McIntosh,1992; in Lewis-Cameron,2015,p.88), a society-centered approach ( Go,1994, p. 331; in Lewis-Cameron,2015,p.88)) and a balanced approach 
(Pring, 1995; Burke, Hawkins \& Schulman, 1990,p.685; in Lewis-Cameron,2015,p.89). They view that there is balanced between theory, knowledge and practical skills.

This is the lifelong learning skills. A work centered approach (Buchicchio, 1991; Koh, 1995; McIntosh, 1992; in Lewis- Cameron, 2015, p. 88) focuses on the importance of tourism education for employability in the industry. A society- centered approach (Co, 1994, p.331; in Lewis-Carmen, 2015, p.88) focuses on tourism education for the sustainable development in the destination.

While using the term "false dualism" to above mentioned approach, pricing suggests to a balance approach for to tourism education. Tribe (2002) advocates for the development of a philosophic practitioner; Mayaka and Akama (2007; in LewisCameron, 2015, p.89) argue for a systems approach to tourism education is needed and Pritchard Morgan \& Ateljevic (2011; in Lewis- Carmen, 2015,p.89) emphasize the transformative power of tourism education to create just and sustainable tourism societies. So far as a balance approach' is concerned, this focuses on the theory, knowledge and practical skills which will balance in between three (Pring, 1995; Burke, Hawkins \& Schulwan, 1990; in Lewis-Cameron, 2015;p.89)

More specially, transformative tourism education must be based on the principle of social engagement, values based and responsible development and sensitivity to industry needs. This balance can be achieved with a focus, on the three core areas of research, education and training which form the core of the proposed tourism education strategy. In addition as Mayaka and Akama (2007, p.303; in LewisCameron, p.93) noted in ten study, a tourism education strategy has to be in live with both the national development plans and the national tourism development policy.

Pritchard, Morgan and Ateljevic (2011) have contributed to tourism studies by providing a preliminary framework for the emerging critical tourism perspective. This framework calls for "hopeful tourism" research which they describe as "... a values-led humanist approach based on partnership, reciprocity and ethics, which aims for co-created learning and which recognizes the power of sacred and indigenous knowledge passionate scholarship (2011,p.449). The authors present "hopeful tourism as a new perspective which combines co-transformative learning and action to offer a distinctive approach to tourism knowledge production" (p. 942). A number of new perspectives have also emerged in the social sciences, which attempt to provide understanding of our transitory times. Three of these - the dynamic feminine (Hill, 1992; Judith, 2006), transmodernity (Ghisi, 2006, 2008) and worldism (Agathangelou \& Ling, 2009) strongly connect with hopeful tourism (Pritchard et al; 2013, p.944).

Echtner (1995,p.33) proposes a "three pronged approach" to tourism education in developing nations. This approach highlights on a combination of three types of tourism education programs: professional, vocational and entrepreneurial. Each of the 
three component focuses on the development of distinct skills, which when combined offer a comprehensive and effective tourism education for the local population in the developing nations. Such an approach to tourism education supplies the qualified manpower needed to strategic level for both the public and private sector (Echtner, 1995, p.33; Kunwar, 2017,p.67).

What is quality in tourism education? According to UNWTO (2014), it is about measuring five areas in education, from the coherence of the study plan to the relevance of the studies to the needs of the industry. Innui et al. (2006) stated that higher education in tourism should be balanced between vocational and academic content (Ritalahti, 2015,p.149).

According to Sheldon and Fesenmaier (2009), educational systems need a change in the skills preparation provided to students, and the way the knowledge is transferred in formal settings to meet the challenges of the next decades. The competitive globalized market requires more trained students in particular in Information and Communication Technologies (ICTs) literacy (Bull et al., 2008; in Sheldon \& Fesenmaier, 2015, pp. 115-116).

Lewis \& Tribe (2002, p.13) suggest, in one way or another, that the global trends taking place in the tourism industry require parallel changes in traditional tourism education toward a global tourism curriculum. Though there is found antiglobalization camp (e.g. Lawton, 1996; Young, 1998), Lewis and Jafari have summed up the concept of curriculum force field and curriculum space (Airey \& Tribe, 2000).

The pedagogical domain driving this work can be addressed in the experiential education perspective which is mainly represented by experiential learning theory ( Kolb,1984; in Sheldon \& Fesenmaier,2015,p.116).In this educational paradigm of "learning through reflection on doing", the concept of "pracademic" (practical and academic) emerged as a new teaching practice (Dredge \& Wray,2012;Posner,2009; in Sheldon \& Fesenmaier, 2015,p.116)where cooperation and information sharing in real world projects between academic and practitioners allow for experimental learning and offer opportunities for academia to serve the community (Sheldon \& Fesenmaier, 2015,p.116).

According to Kolb (1984), experiential learning is "the process whereby knowledge is created through the transformation of experience", and "knowledge results from the combination of grasping and transforming experience". Furthermore, Kolb's theory also emphasizes the importance of learning styles, integrated learning orientations and " the creative exploration of the links between experience, learning, and development across the social spectrum". Kolb's experimental learning model involves four phases : starting from the concrete experience phase a student goes through, followed by the reflective observation phase and the abstract conceptualization phase, to finally 
round up his/her learning in the active experimentation phase. Thus, he states that experiential learning occurs on the basis of relevant experience through reflective processes (1984,p.41;in Cavlek, 2015,pp.104-105). The idea is not only to simply "apply taught theory', but most importantly, to learn to look,see and observe. At the end of the day students learn to do research in a contextual manner (Portegies, Detttaan \&Platenkamp,2009,p.529).

As far as the role and status of educators are concerned, they are the partners in the process of tourism development. They do not exist in a vacuum our knowledge and activities represent our own ideological configurations of a preferred society. Apple (1990; in Inui et al., 2006, p.33) further argues that educators are political beings. Education may take a natural stance that supports common sense or they could take a theoretic stance that studies the nature of common sense and understanding of it (Apple,1990; in Inui et al., 2006, p. 34).Giroux (Inui et al., 2006,p.34) recommends educator provides students with intellectual and moral leadership. Taking the natural instance, our role as educators should be in preparing students to be employable, while the theoretical stance would require ed ucators to facilitate critical thinking and more than skills experts in classrooms, they are" social leaders, cultural advocates, and moral visionaries, spiritual directors, who choose to do their leading advocating , visioning and directing"(Purpel, 1998: in Inui et al., 2006 , p.34). Consequently, the tourism educators need to revisit the focus of the education that they produce for future professionals and scholars.

The focus of education will be on curriculum teaching, learning, assessment, resources, progress and quality of programs, "language" of quality in relation with standards, achievement, experience, quality management enhancement and selection of students (Maureen,2008).

At present there are three modes for the world of higher education: The first one is research mode, the second one is applied mode, and the third one is between the two above. Tourism education notable feature is applied very strong, the overall objective is to develop practical talents, but is different at different levels, undergraduate institutions and above are to train middle and senior management personnel, or white-collared and even the golden-collar professionals; vocational colleges are to train primary and middle management personnel, or grey-collar talents; secondary school is to train skilled service personnel, or blue-collar professionals. Tourism management training objectives can be defined as: training with good overall quality, proficiency in the tourism industry needs all of the professional theory and application of theory of every occupational status, with comprehensively vocational and technical capacity, to meet the $21^{\text {st }}$ century tourism management needs of highlevel and applied talent (Mao \&Wing, 2010,p.89). 
Vertical diversity in tourism work is represented by a more traditional classification that ranges from unskilled through semi-skilled to supervisory and management. This 'traditional' perspective of work and, therefore, skills in tourism is partly described by Riley (1996; Baum, 2006) in terms that suggest that the sector is dominated by semiskilled and unskilled employees (64 per cent) and that knowledge-based positions account for as few as 14 per cent of the total workforce. This simplification masks major business organizational diversity in tourism, reflecting the size, location and ownership of tourism businesses (Baum, 2006:131). The argument that tourism is moving towards increasingly multi-skilled models of training and work has been aired since the early 1980s (Baum, 2006, p.134).

The need is for integrated, coordinated, cohesive delivery and communication systems which inform, serve and support tourists and prospects on a global basis. This new focus demands an innovative method of developing tourists' experiences in an effective and efficient manner. This process focuses on what individuals and prospects want or need to know about products and services, not just what marketers want to tell them. It must be interactive. An integrated, coordinated decision system and collaboration platform should inform, assist and support customer's experiences. In order to succeed in the future destination managers need to interpret 'the new game rules' and re-define 'efficiency' (' doing things right'), 'equity' ('doing the right things') and 'effectiveness' ('doing the doing the right things right' right') on a global scale (Telfer \& Hashimoto, 2006,p.145).

Teaching involves more than ' teaching' and 'learning'. It is composite concept that implicates complex concepts and activity processes. Teaching is also an activity that involves interpersonal interactions between the teacher, learner and language, which in turn changes the learning attitudes of learners or the overall process by which teachers and students jointly share and explore accomplishments, achieving the objectives and ideas or education ( Kyriakides, Campbell \& Christofidou, 2002 ; in Ko \& Chung, 2014, pp. 11-12). Dewar (2002 ; in Ko \& Chung, 2014, p.12) showed that empathy, accessibility, and good presentation are the most important issues in being a good teacher. In summing up the definitions of these scholars (Borahan \& Ajarati,2002 ; Deming, 1982 ; Juran, 1986 ; Whyte, Wyne, Stuck \& Coop , 1987 ; Dewar,2002; in Ko \& Chung, 2014, p.12) for the meaning of quality, this study extends "quality" to teaching quality : promoting common understandings of instructional guidelines and school policies among teachers and being able to satisfy student needs and create unique and appropriate characteristics in the instructional process, and that teachers' services and instructional goals can satisfy the expectations of students and parents, in turn eliciting student potential to achieve the educational objectives expected by students and parents (Ko \& Chiu, 2011 ; in Ko \& Chung, 2014, p.12). 
The existing tourism education programs, course materials and teaching styles, should not be imported directly from the developed world into developing nations. In fact, even those programs designed especially for developing world will likely to be modified to adapt to the unique characteristics of a particular national setting (Echtner,1995,p.32).

Less than $1 \%$ of research on tourism education addresses the issue of learning resources (Tribe, 2005 a, 2005b, 2005 c; in Fidgeon, 2010) has called for the development of learning support networks for educators. Such networks recognize Busby's (1995 ; in Fredgeon, 2010) concern for the changing role of staff as educators and a key learning resource for students. In this context Busbyy considers the continual need for staff development. Tan and Morgan (2001 ; in Fidgeon, 2010, p.702) concluded such initiatives are in developing quality education and a quality curriculum.

... the aim of any programme adopting such an approach to curriculum design is, according to Birch (1988) to enable students to become operational and make a smooth transition into the world of work. Technical skills and knowledge underpin the curriculum with students earmarked for the role of potential manager (Fidgeon, 2010,p.708).

The outcome of Delphi study, as presented by Koh (1995), shows that the four-year tourism management curriculum should comprise 26 elements classified under four broad educational headings: general education, business education, tourism education and experiential education (based on practicum 1 to 3 levels) (Koh, 1995, p.69).

In the bachelor level, attention should be given on the importance of a foundation of general education drawn from the social sciences and pure sciences with provision for students to experience "work" before graduation (Ritchie, 1993; in Koh, 1995, p. 71) including written communication skills, entrepreneurial skills, micro computer literacy, knowledge of hotel-restaurant operations, and delivering quality service without compromising ethical values ( Pollock \& Ritchie, 1990; in Koh, 1995, p.71).

If the tourism discipline hopes to gain professional recognition curriculum diversity cannot be allowed to continue because professionalism demands standardization. As the President of the Society of Travel and Tourism Educators once appealed:

Tourism education cannot be allowed to follow the same willy-nilly pattern of widely varying content and quality that characterized the early year's traditional recreations and leisure programs (Howell, 1986, p. 62;in Koh, 1995, p.71).

Truly, with increasing international competition, it is not education that will save us, but education of a certain kind (Orr, 1990, p.351; in Koh, 1995, p. 71).

The transformative approach to tourism development seeks reconceptualization of tourism's role whereas a passive approach to tourism development views tourism solely as an industry to be exploited for economic gain. A transformative approach 
views tourism through three lenses- as an industry, a revitalization tool, and a social force. As an industry, there has to be a shift from an almost total dependence on high density/high-impact styles of mass tourism to a greater embracing of more low density/ low impact alternatives. In the words of Hall (2010,p.131;in LewisCameron,2015, p.87), the end goal should be "steady-state tourism" which he refers to as "a tourism system that encourages qualitative development but not aggregate quantitative growth to the detriment of natural capital.

In this regard, Engel (1997), as cited by Mayaka and Akama (2007), developed a systems approach for studying tourism in better way. Systems perspective focuses on how coordination can be achieved among factors in complex innovation situations without one group or individual imposing their views. Systems approach has been developed as a way of probing and dealing with complex real world situation (Engel, 1997; in Mayaka \& Akama, 2007, p.301). Systems approach is a useful way of studying the interconnectivity and existing linkage of things and looking at complex interrelated issues and events from a holistic perspective (Mayaka \& Akama, 2007, p.301). However, systems approach has had limited application in tourism. Leiper $(1979,1995)$ applied this in the spatial interpretation of the tourism phenomena, while Mirrison and Roberts (1985) used it from a marketing perspective. Laws (1997), on the other hand, analyzed the inclusive tour business using a systems model. There is room to apply in more tourism innovation and interventions. The approach accommodates concepts such as diversity, multiplicity relationships, synergy, communication flows and interdependency (Engel, 1997; in Mayaka \& Akama, 2007, p. 301). In the light of the forging discussions, a systems model can be a useful tool in analyzing key issues as well as enlisting meaningful interventions in tourism training and educations (Mayaka \& Akama, 2007, p.301).

Instead of systems approach, Knowles (1984; in Mayaka \& Akama, 2007, p.304) has proposed process approach, which is more learner cantered that meets the needs of the teacher and for a curriculum to be relevant to the prevailing context, the process of curriculum design and development should take into consideration the whole environment in which the learning process takes place. Two inter-related concepts are critical in understanding a learner- centred approach namely horizontal integration and vertical articulation. Horizontal refers to inclusion of various factors that affect the learner during the learning process. All these environmental attributes will affects the attitudes overall performance and ability of the learner to grasp the knowledge, skills and professional competency.

It is therefore a systematic way of looking at various factors that influence the actual learning process. Vertical articulation refers to the integration of different levels of educational institutions including pre-school, elementary high school, university and other forms of educational and skills training institutions that exist 
in a community or destination. In particular, it deals with critical issues as relates to interest, experience, continuity, smooth transfer and concern over future careers and different forms of advanced skills and professional training.

They are Fuchs,Fredman and Ioanides (2015) who have analyzed tourism education introduced in Mid-Sweden University (MIUN) on the basis of experiencebase perspective that included the framework of three pillars. These pillars reveal the interface between interacting individual disciplines and tourism. Pillar one, on tourism-related resources, focuses on the sustainable treatment of natural, cultural, and socio-technical resources devoted to tourism production. Pillar two, on consumer behavior, investigates behavioral and attitudinal aspects of tourists related to the consumption and experience of tourism services. Pillar three, on tourism management, focuses on the functioning and the interplay of operations and processes within and among tourism organization (Fuchs et al., 2015,p.62).

In their study Airey and Johnson (1999) concluded that tourism degrees were dominated by highly vocational aims. Top twenty aims and objectives of tourism degree courses

$>$ Tourism offers exciting career opportunities

> Tourism offers employment/ employer limits

$>$ Tourism is a large, global, growth industry

$>$ Tourism allows the application of skills/theory

$>$ Tourism offers international (career) opportunities

$>$ The course develops business/management skills

$>$ Opportunities exist in the private/public sector

$>$ The course develops transferable skills

$>$ The course provides a sound academic education

$>$ Tourism provides abroad foundation for study

$>$ The course aims to meet the needs of the tourism industry

$>$ It develops analysis/judgement/understanding of decision

$>$ The course takes a European perspective

> It broaches social/sustainable concerns

$>$ It develops professionalism and professional attitudes

$>$ The course emphasizes quality and excellence

$>$ It aims to develop flexibility 
$>$ It broaches understanding of service and service delivery

$>$ It aims to develop successful graduates

$>$ It seeks to develop an understanding of competitive forces

(Source: Airey and Johnson (1999; in Fidgeon, 2010, p. 705)

Even today most courses continue to be 'product- led' aimed at appealing to the basic instincts of their educational market (Witney, 2005; in Fidgeon, 2010, p. 707).

Caton (2012; in O’Mahony \&Salmon, 2015,p.133), for example argues for a more philosophical direction in tourism and asserts that moral philosophy should be given a more prominent place in tourism scholarship. She advocates a moral and ethical focus in tourism development and tourism education along with the development of ethics in tourism service nothing that ' traditionally, higher education was envisaged as a truly public good, in the economic sense of the term'(p.1922). Moreover, knowledge created within the university environment was shared within society by graduates thereby contributing to the enlightenment of others within community. In today's neoliberal world, however, education is considered a private good, that is saleable product of commercial value s(O’Mahony \& Salmon,2015,p.133).

The basic premises of both Tribe's (2002) description of Philosophic Practitioner Education (PPE), and Dredge et al.s (2012) description of the curriculum space, lie in the balance that is needed to create s workable curriculum in TH\&E, which satisfies the different learning outcomes that different stakeholders evaluate as necessary for students to have by the time they graduate. Education is generally given value for the goodness it brings to the individual who is its recipient, but even more importantly through the increased value that individual represents to the society in which they will function after the education is completed ( Edelheim, 2015,p.32).

\section{Curriculum}

The term curriculum has taken on a variety of meanings and attention will initially be focused on clarifying its various meanings and its boundaries. A simple definition of the curriculum can be found in Taylor and Richards (1979; in Tribe, 2015, p. 20), who define the curriculum as that which is taught. Tribe (2002a) defines the curriculum as the 'whole educational experience packaged as a degree program' and which may include knowledge, skills, assessment, learning experiences and so on (p. 339).

'A curriculum is the organization of knowledge for transmission in education' (Tribe, 2000,p. 810). However, they are also broader than disciplines, meaning the curricula may also exist for fields of study that do not quality under strict criteria as disciplines. The relevant point is that notions of compartmentalization of knowledge (disciplines, but not only) may also express themselves in curricula - potentially providing insights not only into the teaching, but also into the disciplinary status. 
More complex definitions include that used by Kerr (1968; in Tribe, 2015, p.20), which embraces a much wider experience capturing all the learning which is guided by the institution. There are many definitions of the term curriculum. However, for purpose of simplicity, curriculum can be defined as the program of educational experiences that is packaged as certificate, diploma or degree programs (Tribe, 2005). Various models have been applied to the process of curriculum design (Bligh, 1975; Hirst, 1978; in Mayaka \& Akama, 2007, p. 304). These theories are no less applicable in tourism training and education than in any other field (Mayaka \& Akama, 2007, p. 304).

Curriculum should be designed to respond to the needs of tourism industry to satisfy customers and to produce economic benefits. At the same time, the curriculum should educate students to be reflective individuals who are capable of examining and questioning the social responsibilities of the industry (Inui et al., 2006, p.32)

Tribe (2005; in Mayaka \& Akama, 2007, p.300) provides a useful documentation on historical progression of research on various aspects of tourism training and education in the past two decades including curriculum design, teaching and learning student progression and achievement, leaving resources and quality management and enhancement. Furthermore, there exist diverse approaches to curriculum design and development due to interdisciplinary nature or tourism, as well as the multiplicity of stakeholders. (Mayaka \& Akama, 2007, p. 300).

John Tribe (2015) defines the curriculum as a whole programs of educational experiences that is packaged as a degree program. Its constituent parts are a number of modules or courses, which in turn may be specified as a series of syllabi or course contents (p.20).

When the context of curriculum comes, it needs to consider about its philosophical and sociological inquires. Philosophically it considers methods, key concepts, aims and ideologies. Zais (1976: 317; in Maureen et al., 2009,p. 191) defines, "education is directed toward expanding ones awareness of human environment and how to cope with this environment". “... is tourism higher ideological? Ideology refers to an overarching network of guiding ideas that frame direct and inform thinking. Ideology has been defined as A structure ... structures can captures, can impose themselves; but they can usually be entered willingly, they can be abandoned and they can even be demolished and new ones created in their place ..." (Barnett, 2003,p.57; in Maureen et al., 2009:,p.193). Ideology within the context of (tourism higher) education has been analyzed mainly in terms of curriculum planning and knowledge (Barnett, 2003; in Maureen et al., 2003,p. 193). In the context of tourism education, the scholars have focused on neoliberal policy.

Sociologically it includes the impact of academic culture and networks on 
curriculum. While designing the curriculum, Tribe (2015, P: 20) has proposed two possibilities of approaches.

Curriculum space is defined as "the expanse or area that contains the range of possible contents of a curriculum (Airey \& Tribe, 2000, p. 282). The point about this space is that it is unbounded and includes all possibilities. But any actual curriculum involves a choice and a framing (Bernstein, 1971; in Lewis \& Tribe, 2002, p.18). Because of this the curriculum is necessarily a contested concept. Curriculum space is filled with knowledge, skills and attitudes. Students take educational journeys through different parts of curriculum space and according to the routing of their journey (i.e. the curriculum they follow) they will be exposed to different packages of knowledge and end up in different places with different perspectives, attitudes and competences (Tribe, 2015, p.21). Here it is noteworthy to mention about the idea of curriculum framing. This helps to understand the point of curriculum space. Bernstein explained the term framing thus: [Referring to] the degree of control teacher and pupil poses over the reflection, organization and placing of knowledge transmitted and received in the pedagogical relationship (p.50; in Tribe 2015, p.21).

\section{Curriculum space Model}

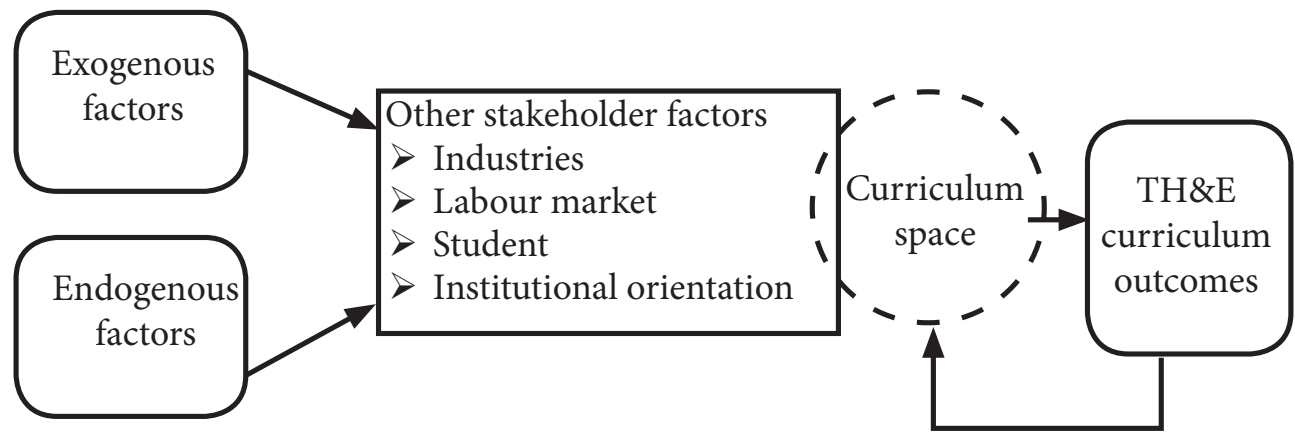

Fig: Curriculum space model(Mayaka \& Akama, 2015,p.246)

The figure recognizes the TH\&E curriculum space as a flexible and adaptable initiative with many possible outcomes which may include but are not limited to employability, the individual ambition and lifelong learning and broader societal aspirations. The curriculum space is a product of exogenous factors, i.e. economics, socio-cultural and technological factors, and endogenous factors that are related to the internal capabilities and constrains of the institutions of higher learning. A multiplicity of the stakeholders is recognized within this thinking.

The curriculum space and curriculum development processes are hence reconstructed as socially constructed, institutions are deeply embedded and boundaries between the institutions as a social system and their contexts are blurred. Thus, Priestley (2011) underscores the need for curriculum designers to maintain 
a clear picture of existing contextual factors. In this regard, the model provides a framework for curricula that's not only imparts knowledge and skills to learners, but also provides deeper learning experiences and meanings in the different life worlds.

The above discussions provides the grounds for a holistic conceptualization of the TH\&E curriculum space. The figure draws the inspiration from Schuler et al's (1993) integrated model for the international resource management and relies on Haywood and Maki's (1993) model of the employment/education interface. It also burrows from Mayaka and Akama's (2007) system framework for tourism education. In addition, the model takes account Tribe's (2002) philosophic practitioner model and its attendant developments (Dredge et al., 2012). As articulated by Dredge et al.(2012) a broader consideration of curriculum goes beyond a focus on content. To this end, a curriculum should contribute to knowledge production and meanings in contextual lived worlds (Certina, 2007). The inclusion of the different stakeholders values is an important element of a holistic approach to TH\&E curriculum space.

T\&H curricula are socially constructed from the interactions, tradeoffs and choices made by a range of stakeholders including academic educators, university managers, students and industry employers (Sigala \& Baum, 2003; in Dredge et al., 2012, p. 2160). Tribe's (2002a) conceptualisation of a PPE that integrates philosophic and vocational ends to develop worldmaking, ethical professionals has received considerable backing from the academic community (Ring, Dickinger \& Wober, 2009; Belhassen \& Caton, 2011; in Dredge et al., 2012, p. 2160).

With the multiplication of new courses in tourism, especially since the early 1990's and greater diversity of approach to curriculum design has come uncertainty among curriculum planners about what to include and exclude in tourism curriculum (Holloway, 1995 ; in Fidgeon,2010,p.709).

Debate contributed to the establishment of a national conference bringing together academics and members of the tourism industry in December 1994, At this conference 'seven areas of knowledge' were advanced by a National Liaison Group (NLG) in the United Kingdom for Higher Education in Tourism an academic body established one year earlier(Fidgeon,2010,p.709).

This tension between tourism professionals and tourism faculty in curriculum design is often resolved through the integration of the scholarly and practitioner philosophies. One form of integration is a curriculum based on the scholarly philosophies of understanding tourism as a social science, plus the industry philosophy of a foundation of industry competencies (Hill, 1992; in Obenour et al.,,2005,p.45). Jafari and Ritchie (1981) labeled this integration as a mix of conceptual learning and skill development. 
Committee members of the NLG were given a brief of developing a core curriculum that would not only satisfy employers, but would also maintain academic rigor and meet the needs of students for an educationally enriching and relevant program of study. Transferability of skills was also recognized as it was thought any tourism program should provide the basis for careers in other service industries (Fidgeon,2010,p.709).

The areas of knowledge identified included:

Understanding the meaning and nature of tourism. This includes definitions, social and other conditions and determinants of tourism and tourism motivations.

$>$ The structure of the industry. This was to encompass a description and interrelationship of the main component sectors of the tourism industry and their operating characteristics.

$>$ Dimensions of tourism and issues of measurement. Here the scope of the tourism industry, its spatial dimension, patterns and determinants of demand, the resource base of tourism and sources of tourism data and management information would all be broached. The significance and impact of tourism. This was to consider the costs and benefits of tourism from a social economic and environmental perspective.

$>$ The marketing of tourism. This included general marketing theory and an analysis of consumer behavior as it applies to tourism.

$>$ Tourism planning and development. Destination and site planning, the financial implications of planning, partnership issues and sustainable tourism were all considered appropriate areas for study.

$>$ Policy and management in tourism. This was to address issues pertaining to public sector policy and corporate strategy. Organizations in tourism and visitor management issues were thought to compliment this study (Fidgeon,2010, pp.709-710).

The case for and against a core curriculum has been extensively argued (Cooper, 1994 ; Tribe, 2006). In essence debate has centered on how core curriculum would guarantee a reliable supply of educated professionals to a developing and expanding worldwide industry. The counter argument maintains that a fixed core curriculum does not encourage development of this field of study. The limitation of tourism subjects to a core curriculum at a comparatively early stage in the development of the discipline might further exclude the study of emerging issues. All are valid arguments (Fidgeon,2010,p.709). 
The curricula offered by the aforementioned international $\mathrm{PhD}$ programs in the field of tourism have been thoroughly inspected. According to the finding of these reviews, the thematic subjects that their students undertaken research on can be placed in six groups: destination management and strategy planning (destination marketing, visitor management and demand modelling, carrying capacity, and social and economic impacts of tourism); operations at tourism organizations (service production and quality management, information systems management, human resources management and accounting, finance, and yield management); organization studies in tourism (leadership and entrepreneurship, innovation and new product development, and internationalization and foreign direct investments); responsible tourism (ecotourism, environmental policy, ethics, sustainable tourism, authentic production/consumption, and pro-poor tourism); specialinterest tourism(convention, sports, nature-based, wine and food, and culture tourism, as well as festivals and management of events and attractions); and tourism and climate change(adaptation and mitigation strategies to deal with global climate/environmental threats (Fuchs et al., 2015,66).

The first is empirical research then collect data and ask basic questions such as: what do students want? What do employers want? What do academics want? What are job related needs? This seems easy enough and many studies have pushed this path. But this approach only begs a further question. The question is: what is the curriculum for? These questions enhance to understand the meaning of curriculum in better way.

\section{Tourism Bachelor Program}

Profile: Ability to understand the scientific, technical, social, economic and cultural aspects of tourism markets, their expansion and management. To observe stages in decision making processes, process, present flexibility and adaptability in contextual scenarios when dealing with different problems- current and future- in various segments of the professional field (Sogayar \& Rejowski,2015,p.214).

Main competences: Interpersonal and intercultural communication ; integration within interdisciplinary teams ; use of creativity within different organizational scenarios ; understanding the complexity of the globalized world, deep experience and knowledge about human relations, adequate technical performance, professional humanism, simplicity, self-assurance, empathy and ethics (Sogayar \& Rejowski 2015,p.214)

\section{Content Curriculum}

Basic content: Studies related to the sociological, anthropological, geographical, cultural and artistic aspects that form societies and their cultures. 
Specific Content: Studies related to the general theory of tourism, communication and information theories, establishing further relationship with tourism administration, law, economics, statistics and accounting and the domain at least are foreign language (Sogayar\& Rejowski 2015,p.214)

Theoretical and practical content: Studies located in the spaces of tourist flow comprising technical visitation, tourism inventory, learning laboratories and internship.

Minimum number of hours: 2,400 (for face-t-face training program) (Sogayar \& Rejowski, 2015, p.214)

Hospitality Bachelor Programme

Profile: To operate in a highly competitive and constantly changing market, with periodic and seasonal impacts, according to changes in social, economic, political business and organizational sectors. It should also emphasize hotel management with important structural infrastructural and to effective functioning and quality according to various cultural segments of hotel demand (Sogayar\&Rejowski, 2015,p.214)

Main component: To be able to integrate within a hotel group and within the unit he/she runs, contributing to the performance of interdisciplinary terms and to interact creatively within different organizational and social context as well as to solve situations with flexibility and adaptability in the face of organizational problems and challenges (Sogayar\&Rejowski, 2015,p.214)

Current curriculum:

> Basic content: Studies related to humanities with emphasis on psychology, sociology and physical geography human, economic and politics and communications science and arts (Sogayar\&Rejowski, 2015,p.214)

$>$ Specific content: Studies related to administration, economics and law applied to the hospitality industry inter linked with tourism, as well studies on communication system and computing including mastery of at least one foreign language (Sogayar\&Rejowski, 2015,p.214)

$>$ Theoretical and Practical content: Obtained by computer system including specific laboratories that will permeate the peculiarities of the hotel industry, supervised and integrated internship extracurricular activities and scientific initiation. Minimum numbers of hours: 2400 (for face to face training progamme) (Sogayar\&Rojowoski, 2015,p.214)

$>$ Tribe (2001, p.447; in Inui et al., 2006, p.26) suggests that:

$>$ “...to design a curriculum to include non-vocational aspects, questions of meaning and purpose of the curriculum arise. It is here that an emphasis on reflective philosophical method becomes necessary." 
European Master in Tourism Management's (EMTM), degree known as Master of Science in Tourism Management, three main objectives are to:

$>$ prepare future professional to strategically manage and make sustainable and effective decisions in placements of high responsibility to tourism institutions;

$>$ Provide future professionals with an integrated knowledge of the dynamics of tourism development, the principles of sustainable management, environmental issues, the role of cultural diversity and creativity for innovation and the governance of tourism networks, the quality management of customer services; and

$>$ Train future researchers in the field of tourism management(Sheldon \&Fesenmair,2015,p.167).

\section{Tourism Curriculum and Body of Knowledge.}

A body of knowledge is the complete set of concepts, terms and activities that make up a professional domain, as defined by the relevant learned society or professional association. It is a type of knowledge representation by any knowledge organization."Structured knowledge that is used by members of a discipline to guide their practice ". (Oliver,G.R, 2012,p.3;Wikipedia).

Diverse tourism models comprising the frameworks for a core body of knowledge have been proposed by Goeldner's (2001) extension of Jafari's and Ritchie's model; Jafari's model (Jafari \& Ritchie, 1981 ; Hawkins \& Hunt (1988; in Obenour, Lengfelder \& Cunneen,2005,p.44); Leiper 1990; and the national leisure group (Airey \& Johnson, 1999).A body of knowledge consisting of core courses for tourism curricula has been debated in the literature concerning tourism in higher education. The literature review of Obenour et al (2005) includes the following areas: (a) arguments on whether tourism is a discipline or a field, (b) the influence of scholar-ship versus practitioner foci on the type of core courses, and (c) advantages and dis-advantages of a standardized core of courses.

Some tourism educators have argued that tourism is a field with an interdisciplinary focus with courses integrated from non-tourism disciplines (Echtner \& Jamal, 1997; Gunn 1987; Jafari \& Ritchie, 1981; Tribe, 1997 ; in Obenour et al.,2005,p.44-45). This educational model of a field melds several disciplines' courses into a focus on tourism with the integration of the concepts part of the teaching approach (Jafari \& Ritchie, 1981). According to Tribe (1997), this is the essence to a field with the study of tourism similar to other educational fields such as engineering and not a discipline. Tribe (1997) advocated two subfields of tourism which were designated tourism business and tourism studies. Tourism studies subfield includes non- 
business topics and courses such as environmental impacts, carrying capacity, and social impacts.

Leiper $(1981,2000)$ argued for the disciplinary approach or tourology based on a general theory of tourism with a distinct tourism faculty and content. Leiper (1981) reasoned an interdisciplinary approach caused a fragmented curriculum with the result of students not understanding the interrelatedness of the tourism phenomena. The disciplinary approach develops courses that are courses that are distinct to the theory and study of tourism. Even with the advantage of distinct tourism faculty and course content, the tourism field and especially the subfield of tourism business has been increasing in popularity (Airey \& Johnson, 1999; in Obenour et al.,2005,p.45).

The body of knowledge contained within the core courses of a tourism curriculum can be derived from a scholarly approach, practitioner approach or a combination of the two approaches (Ritchie, 1988). Kaplan (1982; in Obenour et al.,2005,p.45) defined one group of tourism educational institutions as entities who were proactive and determined the industry needs. This proactive group was characterized by pursuing tourism curricu-lum that was based on a business approach concentrated on analysis, management, and work experience (Kaplan, 1982;in Obenour et al., 2005). The second group of institutions was reactive and asked what industry wants. This approach was characterized by a training approach used by faculty that covered industry skills and functions for a career in operations (Kaplan, 1982).

Educators (Airey \& Johnson, 1999; Buergermeister, D’Amore, Jafari, \& Pearce, 1992; Richards, 1998; in Obenour, Lengfelder \& Cunneen,2005,p.46) identified the benefits for a standard core of tourism courses as the following: (a) facilitate definition of course and teaching objectives, (b) assist in communicating the tourism offerings to the public and industry, (c) facilitate course validation and quality assurance, (d) facilitate the development of conceptual understanding and progression, and (e) facilitate the transferability of credits. The major disadvantages of standardization of the core curriculum are the stifling of innovation and creativity and reduced flexibility in meeting the needs of the industry (Airey \& Johnson, 1999; Dale, \& Robinson, 2001; in Obenour et al.,2005,p.46). Hawkins and Hunt (1988) posit the standardization argu-ment by stating that one curriculum model neither could nor should be designed to meet all of the various elements of the tourism system.

Four perspectives of a tourism core body of knowledge are reviewed and include the following: (a) National Leisure Group in the United Kingdom, (Airey \& Johnson, 1999); (b) Jafari (Jafari \& Ritchie, 1981); (c) Weenen and Shafer (1983); and (d) Koh (1995).

In addition to the core content developed by the National Leisure Group, Jafari and Ritchie (1981) described a tourism framework based on the interrelationship 
of tourism with multiple disciplines. This framework specifies subject areas for tourism which is useful in formulating course titles and content. Churchward and Riley (2002; in Obenour et al.,2005,p.46) utilized a modified version of Jafari's framework to analyze job knowledge of professionals in the United Kingdom. They found market-ing, recreation/leisure, business/finance and economics to be the most common knowledge areas across respondents from diverse industry sectors.

The third perspective of a tourism core body of knowledge was researched by Weenen and Shafer (1983; in Obenour et al.,2005,p.,47). The courses used by Weenen and Shafer were further expanded by Lengfelder, et al. (1994) through the addition of three course topics (historical anthropology of tourism, political geography of tourism, and popular culture/leisure lifestyles).

The fourth perspective advocated by Koh (1995) developed a list of course elements involving 3 different tourism sectors. The course elements were then used to survey tourism professionals with Koh finding 15 course elements, to be very important. In addition to tourism professionals, educators were surveyed and 12 of 26 course elements were significantly different between educators and pro-fessionals. Educators rated significantly higher compared to professionals on courses such as natural resources, societies and cultures, government/citizenship, marketing, marketing research, and laws. Professionals rated significantly higher compared to educators on courses such as managerial accounting, hotel/restaurant operations, and practicum after year three.

\section{Academic Tribes}

They are Becher and Trowler (2001; in Tribe, 2010, p.10) who conducted a comprehensive study in to the general nature of academic tribes and territories. To do this they concentrated on the epistemological properties of knowledge formation (territories)... [And] the social aspects of knowledge communities [tribes] (p.24; in Tribe, 2010, p.10). The term 'academic tribes' has been focused on disciplinary cultures - that is, the rules, norms and acceptable behavior patterns upheld by disciplinary communities - and these cultural influences are evident in tourism. There has been shown the 'elders' of the various tourism tribes as those holding distinguished chairs, those on the panels of research grant award bodies, those on editorial boards and acting as referees of key journals, those on the executives of learned and professional associations... (Tribe, 2004, p.53).

Researchers are also located within academic communities, and Becher's (1989) anthropological investigation of "academic tribes" provides a fascinating insight into acceptable behavior patterns, rules, norms and hierarchies operating within disciplinary communities. Following Becher, it is instructive to consider aspects of 
academic tribalism in tourism. Of particular interest are the "elders" among them whose headdresses are adorned with feathers of esteem - holding of chairs, editorships of key journals, keynote invitations, seats on panels of research grant and assessment bodies, publishers' advisory positions, and positions on the executives of learned and professional associations. For "elders" one could also read "power-brokers," for this group acts as commissioners in the creation of, and gate-keepers in the dissemination of knowledge (McKercher , 2002; in Tribe, 2006, p. 372).

Academic territory refers to the epistemological nature of field and relevant here are the part of Becher and Trowler's study that highlighted disciplinarity, the content of the field (its canon), whether the field contains hard or soft knowledge (paradigm questions) and the mode of inquiry. "Studies" is plural because of the idea of interaction between disciplines (Klein, 1996 ; p. 10;in Repko, 2012 ;p.11).

\section{Philosophic Practitioner}

It would be foolish to approach any serious consideration of the university curriculum without reference to Barnett. In this section I would like to position my work on 'The Philosophic Practitioner' in between one of his classic pieces and a more recent piece. In what must be the seminal text on the subject. The Idea of Higher Education- Barnett (1990: 202-3;in Tribe, 2015,p.24) concludes that there are six ' minimal education conditions' that are necessary to fulfill the condition of higher education. These include:

$>$ A deep understanding of some knowledge.

$>$ A radical critique of knowledge claims.

$>$ Competence to develop critique in the company of others.

$>$ Self-reflection.

$>$ Open dialogue and cooperation.

This is a crucial starting point since it distinguishes higher education from , say, schooling or further education. Of particular note are the needs for deep understanding of knowledge (expertise), open dialogue (disputation) and a critical evaluation of knowledge (skepticism).

Mindful of this challenge I developed the concept of "The Philosophic Practitioner'. It arose from my dissatisfaction with previous research on the tourism curriculum and was inspired by my reading of the wider literature on higher education and particularly of Schon and Barnett (Tribe, 2015,p.24).

Tribe (2002) suggests that the philosophic practitioner seeks to develop:

".....practical wisdom and action in the wider world at the same time as earning a living and contributing to the economic development of a specific business domain 
of tourism . This working in tourism while taking responsibility for stewardship of its developing world"( p.354).

According to Tribe (2002), the philosophic practitioner should have skills and knowledge in all four domains. Moreover, he observes that although the four domains are represented separately in the diagram, in practice they would be integrated in the curriculum model. The Philosophic Practitioner Education (PPE) captures the ambition of T\&H education to meet the demands of industry and promote employability of graduates (Dredge et al., 2012, p. 2157).

The balance between liberal and vocational education within tourism and hospitality $(\mathrm{T} \& \mathrm{H})$ curricula has become an increasingly noteworthy topic of discussion since Tribe (2002a), drawing from Schon's reflective practitioner (1982, 1983, 1994; in Dredge et al., 2011, pp.2154-2155), and the deliberative practitioner Forester (2000; Morgan, 2004; in Jamal, Tailon \& Dredge, 2011, p. 134) argued for a curriculum that nurture the 'philosophic practitioner'. The philosophic practitioner education, as mentioned by Tribe (2002), integrates theoretical knowledge from a range of fields' to encourage vocational competence balanced by ethical competence (p. 340). The PPE requires a curriculum that is composed of vocational, professional, social science and humanities knowledge and skills that promote a balance between satisfying the demands of business and those required to operate within the wider tourism world. Several authors have been calling for this balance in education for some time (Baum, 2005; Inui \& Lankford, 2006; Lashley, 1999; McKercher, 2001; in Dredge et al., 2011, p.2155), but there remain considerable challenges in terms of defining program content, modes of delivery, appropriate pedagogies, skills and graduate capabilities (Tribe, 2000).

Scholarship is the contribution of knowledge that is "public, susceptible to critical review and evaluation and accessible for exchange and use by other members of on one's scholarly community" ( Shulman,1998,p.5;in Repko, 2012,p.11). Contemporary scholarship divides higher education as two broad categories: Liberal and Vocational. Liberal education (Liber=free in Latin) refers to the curriculum that develops general knowledge and fosters complex, independent thinking and transferable intellectual and practical skills. Dredge et al.(2012,p.2156) explain that liberal education ' refers to a curriculum that develops general knowledge and fosters complex, independent thinking and transferable intellectual and practical skills. As these authors contend that liberal education can develop reflection and independent thinking and should therefore be valued for its own sake rather than just for its utility.

Tribe has divided the curriculum space along two axes: the vocational-liberal axis and the reflection-action axis. The first represents the different ends of the curriculum, essentially the degree of vocational focus, and the second the different stance or 
modes of study and expression which the curriculum employs to achieve its ends. In Tribe's words (1999, p.112; in Airey \& Tribe, 2000): Tribe(2002), Dredge et al.(2012) conceptualize curriculum space in the dimensions. These are vocational outcomes that is those that are needed to succeed in tourism and hospitality employment, and liberal outcomes which focus on reflection and freedom of thought. A vocational curriculum is a curriculum for action. It is a curriculum to equip students to engage in the vocational world and to participate in it. A liberal curriculum is a curriculum for study and reflection (p. 285).Tribe (1997) goes on to suggest that: the vocational and liberal not only have different aims in the world of business on the one hand and the field in general on the other, they also equip students to take different stances. These can be identified as an active stance towards the world of work (vocational) and a reflective stance towards the field of study (liberal) (Airey \& Tribe, 2000, p. 285).

Dredge et al.,( 2012,p.2157) also propose ' a balance between vocational and professional skills and the broader critical thinking and analytical skills

Advocates of liberal education argue that it should be oriented towards a social and political ends and in the context of the role the learner can take as a' good citizen' in the future( Farbham \& Yarmolinsky, 1996; Nussbaum, 2010; in Dredge et al., 2012, p.2156). The purpose of a liberal education is to provide an enculturation process that develops an awareness and ongoing ability to critically reflect on the intellectual world (Wegener, 1978; in Dredge et al., 2012, p.2156), preparing graduates for free thinking citizenship. Vocational education (Vocatio="call" in latin) provides training and practical skills for a specific trade or occupation. Professional education represents a merging of both liberal and vocational education whereby the learner engages in specialized education training for a particular occupation (Lum, 2009; in Dredge et al., 2012, p.2156),).

Morgan (2004; in Inui et al., 2006,p.28) suggests shifting the educational focus from a rigorous vocational framework to a liberal reflective approach in order to address this issues."Paradoxically, vocational higher education in tourism may need to rediscover these humanistic values in order to fulfill its managerial objectives of creating successful business manager "(Morgan, 2004, p. 98).

It is noteworthy to mention the concept of Aristotle in this contrext. The term 'phronesis' is derived from Aristotle's (1980) Nicomachean Ethics wherein the contributions of scientific knowledge (episteme) and technical knowledge (techne) by themselves are understood to be insufficient in determining good professional action (see Flyvbjerg, 2001, 2004; in Dredge et al., 2012, p.2156),). For Aristotle, phronesis, defined as practical wisdom or prudence, is also necessary. In Aristotle's view, phronesis requires actors to draw not only from episteme and techne, but also from maturity and experience (i.e. prudence), to determine good and virtuous actions. 
(Dredge et al.,2012, p.2156; in Jamal, Taillon \& Dredge, 2011, pp.133-137). Praxis (social change) will be also used in the area of tourism studies.

Much of this literature cites the work of Tribe (2002a, pp. 340-1) who conceptualizes the curriculum space in terms of two dimensions: ...ends and stance. The first relates to that part of the world which is the focus of the curriculum, and the second to how the curriculum promotes engagement with these ends. Ends are represented by an axis of purposes toward which the curriculum is constructed and aimed. These include vocational ends of employability and liberal ends focused in freedom of thought about tourism... The stance axis describes different modes of study and expression which promote the curriculum's ends. The alternative stances that can be adopted in tourism education are reflection and action.

The vocational-liberal axis runs from curricula that are concerned with the world of work to those that focus on the world of study. The action-reflection axis extends from curricula where students are involved in the world and are engaged in putting ideas into practice to those where the engagement is with the cognitive processes of the mind (Airey \& Tribe, 2000, p. 285).

Vocational versus Liberal Curricula

\begin{tabular}{|c|c|c|}
\hline & Vocational tourism studies & Liberal tourism studies \\
\hline Aim & $\begin{array}{l}\text { To produce an effective labor } \\
\text { force }\end{array}$ & Understanding tourism. \\
\hline Research Methods & Positivist & $\begin{array}{l}\text { Interpretive } \\
\text { Critical }\end{array}$ \\
\hline Values & Tourism for profit & $\begin{array}{l}\text { Search for competing values } \\
\text { Public interest }\end{array}$ \\
\hline Approaches & $\begin{array}{l}\text { Functional modules } \\
\text { Transferable skills }\end{array}$ & $\begin{array}{l}\text { Disciplinary approach } \\
\text { Critical module } \\
\text { Research methods and } \\
\text { project } \\
\text { Complementary studies } \\
\text { Great books }\end{array}$ \\
\hline Research & Industry-led & $\begin{array}{l}\text { Issue-led } \\
\text { Search for hidden issues }\end{array}$ \\
\hline Evaluation & Performativity & Better Understanding \\
\hline
\end{tabular}

Source: Adapted from Tribe (2002).

The above mentioned table shows that Tribe has recommended a balanced approach in between both vocational versus liberal curricula.

This has still created a tension among scholars as in many institutions of higher education offering courses in tourism and hospitality- often in the same schools or 
departments-there is a divide in between tourism as an area of academic and critical study and hospitality which has commonly offered as a vocational program. Indeed, the tendency for tourism education to be increasingly influenced by neoliberal, market-led approached has been noted by several writers (Ayikoru et al.,2009).

Holden and Wickens (2007;in Harrison, 2015, p.227 ) are especially critical of this trend, which results in tourism courses becoming more vocationally and business oriented, and increasingly being considered ' a means of supporting industry and commerce'. For these authors, this is a 'myopic view' which : risks producing a reductionist model of higher education. If courses are skewed to the needs of business, module content decided on the rationale of what is useful to business, where is the space to produce analytical, free-thinking and orthodox-challenging citizens of the future?(Holden \&Wickens,2007:46; in Harrison, 2015, p.228)

However, it is now over 10 years since Tribe presented the PPE, and whilst the core principles of the framework remain sound, the present higher education context is significantly different. In this context a number of points are raised about the PPE (Dredge et al., 2012, p. 2158).

So, while the PPE is a thought-provoking abstract representation of the tradeoffs made between reflection-action and vocational-liberal knowledge, since its development there have been significant advances in thinking about the social construction of knowledge and the dynamic processes associated with knowledge accumulation and life-long and life-wide learning. To this end, it is important to rethink the debate over what constitutes a PPE in T\&H education (Dredge et al., 2012, p. 2159).

Mainly for simplicity, we treat business/management as a discipline. However, we acknowledge that some have doubts about this, and see business/management as a mature field (see Tribe, 1997). A field is rather 'an object of study' (Tribe, 1997:653). We use the theme as a unifying line of thought within a 'context of application' (Gibbons et al., 1994:168), which is however less circumscribed and less established than a field. A competence is an 'ability to solve a problem' (Tribe, 1997:654) and a problem is 'a concern of people' (Cohen et al., 1972:3; in Volgger \& Pechlaner, p.93). In all of the identified cases this single discipline is business/management, meaning that what is taught is essentially the business of tourism. The curriculum is similar to a standard curriculum in business/management with some dedicated courses that discuss specific features of TH\&E as a field of application. Thus, paralleling Tribe's (1997) terminology, we could call this approach the business disciplinarity of tourism.

Over time emerged a more inclusive hospitality studies approach which reflects on the connections of hospitality to society as a hold, and the locations of the world 
of business and management therein (Lashley et al., 2007; in Morrison \& O'Gorman, 2008, p.214). This stance embraces literature and theory of multiple genre and discipline, including the social science. Further, it supports reciprocal applications between the intellectual constructs and practices of both hospitality, and business and management. Hospitality subject development has now reached a point where there exists growing acceptance of the potential for, and virtue of, a symbiotic management and studies (Morrison \& O'Gorman, 2008, p.214).

Within a higher education context, the journey from hospitality's historic origins and association primarily with management to a contemporary situation that supports the inter-relationship between and co-existence of, management and studies schools of thought has been traced, and academic advancement identified. Specially, it recognizes hospitality's 'late entrant' status as a university subject (Morrison \& O'Gorman, 2008, p.215).

The above mentioned discussions highlight the need for skilled tourism and hospitality management practitioners who can manage change in positive, creative world-making ways. Therefore, implications for the T\&H curriculum to look beyond business education and embrace a broader social science education are quite clear. The tourism curriculum needs to develop a society for all stakeholders and not just a society for business (Sheldon, Fesenmaier, Wober, Cooper, \& Antolioli, 2008; Tribe, 2001; in Dredge et al., 2012, p. 2160).

There are common core knowledge and skills which form the basis of academic standards for T\&H education and the PPE will be developed depending upon the institution, some contexts, some industries and communities. Whilst other authors have discussed the balance between liberal and vocational education. Dredge et al. (2012) incorporate the notion of a 'force field' of influences on T\&H education.

\section{Professionalism and Competencies}

Professionalism is a rather nebulous term as it implies not only a profession and the skills, competencies or standards associated with it, but also an attitude and behaviour that reflect these. It has also been defined as the ability to align personal and organizational conduct with ethical and professional standards that include a responsibility to the customer or guest and community, a service orientation and a commitment to lifelong learning and improvement. Professionalism is defined as incorporating leadership, a practical approach (practicality), attention to services, concern for the relevance and timeliness of evidence, reflexivity, teamwork and partnership-building skills, and proactivity. Proactivity involves taking the initiative to address problems in one's service domain and commitment to excellence in one's domain of expertise. (Sheldon \& Fesenmaier, 2015,p.161). The core value of professionalism are a requirement for all tourism and hospitality academic programs. 
It is educators' responsibility to expose students to high-quality and appropriate professionalism. The term 'new professionalism' is used by Sachs (2003); in Sheldon \& Fasenmaier, 2015, p.161) to distinguish between 'old forms of professionalism which debate characteristics of professions and the extent to which occupational groups might be acknowledged as professions, and 'new' forms which claims Sachs (2003) assume a 'changed' analytical perspectives' and are seen to be more positive, principled and post-modern' (p.182; in Dredge et al.,2015,p.161). While there is no overall agreement as to what constitutes a profession, certain key aspects are commonly cited that seek to professional status. These generally include reference to specialist knowledge, autonomy and responsibility( Hoyle \& John, 1995; in Sheldon \& Fasenmaier, 2015, p.161). Professionalism therefore, implies that such characteristics are evident in an individuals' work (Sheldon \& Fasenmaier, 2015).

Professional tourism education is academic in nature. Theoretical concepts are provided and the students' ability to interpret, evaluate and analyze are developed (Cooper \& Westlake, 1989 ; in Echnter, 1995, p.33). The ultimate goal of professional education is a broad understanding of the tourism industry and its unique issue and challenges. Such an approach to tourism education supplies the qualified manpower needed at strategic level for both the public and private sectors (Echnter, 1995,p.33). The complexity of the tourism industry, together with the need to develop a comprehensive view of the subject, indicates that professional education is best accomplishes at a tertiary (University) level (Echnter, 1995,p.33).

The terms 'competency' and 'key competencies' has attracted many scholars of tourism and hospitality education (Lowry \& Flohr, 2005) and 'key competencies' (e.g., Zehrer \& Mossenlechner, 2009; in Su, 2015, p.323) rather than ' basic skills' and 'technical skills' to describe the ability of tourism graduates to address the indeterminacy and uncertainty of tourism practices. Competencies is a combination of observable and applied knowledge, skills and behaviors that create a competitive advantage for an organization. It focuses on how a employee creates value and what is actually accomplished (Nath \& Raheja, in Jauhari \& Mishra, 2004 ;in Jauhari , 2006, p.123). Chung-Herrera et al. (2003; in Jauhari, 2006,p.123) postulates that a competency model is descriptive tool that identifies knowledge, skills, abilities and behavior needed to perform effectively in an organization meet its strategic objective through building human resource capabilities, competency modeling focus on behavior rather than personality traits. Human resources comprise a very important aspect of management of services. Competence is typically considered to be a holistic concept (Rychen, 2004,p.22; in Su, 2015, p.323) that consists of 'a combination of knowledge, skills, attitudes and values' (Hoskins \& Fredriksson, 2008:11; in Su 2015, p.323) and possesses cognitive and non-cognitive dimensions (Rychen \& Salganik, 2003,p.43; in Su, 2015, p.323). Zehrer and Mossenlechner (2009; in Su, 2015, p.323) 
enumerate four types of competences (professional competences, methodological competences, social competences and leadership competences), whereas LopezBonilla and Lopez-Bonilla (2012; in Su, 2015, p.323) consider that the content of different competencies may be developed depending on whether a person is 'learning to know', 'learning to do,' 'learning to develop attitudes'.

In a keynote address given at the 2011 Surrey Tourism Conference ,held in celebration of the twentieth anniversary of the publication of special issue of Annals of Tourism Research on 'Tourism Social Science', Professor Annette Pritchard asked the audience to consider whether tourism studies has become 'a house divided'. Tourism studies has been cogently described by Tribe (1997-2000) as bisected field-with one portion addressing its business-oriented features and other portion being dedicated to its analysis from a social science perspective-and Pritchard was querying the audience about the degree to which each of these sides of tourism studies genuinely respects and engages with the knowledge base of the other side, ultimately raising questions about our sustainability as a field if we carry on in our current dived manner (Caton, 2015, p.44).

Indeed, critiques of the traditional Tourism, Hospitality and Events (TH\&E) curriculum generally emphasize the importance of embracing both social science and business concerns, arguing that the latter tends to be advance at the expense of former (Tribe, 2002, 2008a; Inui et.al. 2006; Ring et. al., 2009). In support of broad curriculum that transcends simply vocational concerns, Tribe's (1997) diagram of epistemological domain of tourism nicely illustrates the idea that tourism knowledge can and should derive from a thick base of diverse disciplines each of which can contribute in its own way of approaching the phenomenon. The diagram depicts tourism studies as a central object surrounded by a band of disciplines -including sociology, geography, political science, law, psychology, philosophy and economicswhich contribute to its development as an area of study.

This situation is echoed in the intellectual landscape of dissertation study as well, with history, a discipline of quasi-humanities and quasi-social science pedigree, standing as only representative of the humanities in Weiler et al's (2012; in Caton, 2015, p.44-45) assessment of top 14 disciplines informing tourism doctoral study in the United States, Canada, Australia and New Zealand. Tourism education may well be a house divided, with business and social science concerns tugging against each other, but the humanities - a major part of the essential foundation of true liberal arts education-haven't even made it to through the door. This represents a lost opportunity, for the humanities have great deal to offer TH\&E higher education.

Generally speaking, in less developed Asian countries tourism education is struggling because of limited educational resources, including teaching facilities, 
qualified faculty, updated teaching materials, and expertise in curriculum development. These issues are not unique to Asia, but are common for all underdeveloped and developing countries (Caton, 2015, p.44-45).

\section{Tourism as Discipline or Indiscipline?}

A discipline can be defined as 'a distinctive body of knowledge' and an organized set of rules and conceptual structure for advancing knowledge" (Tribe, 2000, p. 810). A discipline can be categorized by the following criteria (Hirst, 1974; in Volgger \& Pechlaner, 2015, p.86): (1) a web of interrelated concepts; (2) a particular logic structure that blinds the concepts; (3) testability within this web using its particular criteria and logical structure; (4) irreducibility to other disciplines. According to similar approaches, disciplines consist of webs of constructs (theories), methods (ways of producing and testing knowledge and aims of application domains (Donald, 1986; Toulmin, 1972; in Volgger \& Pechlaner, 2015, p.86)). Some authors additionally request the existence of a dedicated community, means of communication (such as journals), tradition and a set of values (King \& Brownell, 1966; in Volgger \& Pechlaner, 2015, p.86). Disciplines do not coincide with curricula; however they are intertwined.

Disciplines are probably the most structuring principle in academic knowledge generation and delivery. They are related to a division of labour within academia and different institution (faculties or institutes)... (Volgger \& Pechlanar, 2015, p.86).

It has been tempting for some writers to interpret the development of tourism studies as an evolution towards disciplinary status. Disciplinary status would provide the necessary tools and framework for promoting sound tourism knowledge. Tourism knowledge would become self-refereeing within its discipline, knowledge quality control would be assured, and tourism academics would take their place on an equal par with those from other disciplines (Tribe, 1997, pp. 642-646).

Does tourism studies constitute a discipline? This is a difficult question, and it is not one that the editors were able to agree on, even almost themselves. However, we do take note of Johnston's, (1991; in Hall, Williams \& Lew, 2005, p. 9) reflection that: there is no fixed set of disciplines, nor any one correct division of academics according to subject matter. Those disciplines currently in existence are contained within boundaries established by earlier communities of scholars. The boundaries are porous so that disciplines interact. Occasionally the boundaries are changed, usually through the establishment of a new discipline that occupies an enclave within the pre-existing division of academic space.

The conclusion drawn, within this perspective is that tourism is an object of study (field) rather than a way of studying (discipline)' (Tribe, 1997,p. 653). Cooper et al. (1998 : in Volgger \& Pechlaner, 2015,p. 86).) hold similar position In contrast, Leiper 
(2000) and Goeldner (1988) are major components of the 'tourism as a discipline' view; especially Leiper (1981) sees a need for developing interdisciplinary accounts into a general and systematic discipline of tourism ('tourology'). Finally a third group of authors maintains a prudent position. For instance, Echtner and Jamal (1997, p. 880 ) argued that while tourism studies could potentially develop into a discipline, it is concluded that there are many practical and philosophical reasons that hampers its evolution' (Volgger \& Pechlaner, 2015, p.87).

Jovicic (1988; in Echtner \& Jamal, 1997, p. 869) makes a plea for the establishment of "tourismology", or a distinct science of tourism. He argues that the study of tourism as a complex phenomenon cannot be adequately addressed from within anyone existing discipline. He further suggests that the various disciplines that currently house tourism studies, including economics, sociology, and geography, “ $\ldots$ fail to grasp the notion of the whole and endeavor to explain the entity which is tourism by its individual aspects" (1988, p.2; in Echtner \& Jamal, 1997, p. 869). According to him, only the emergence of a distinct discipline, such as tourismology, will allow for the development of an integrated theory of tourism. Tourismology would facilitate the merger of the specialized studies now occurring within diverse disciplines and would allow tourism to be examined as a composite phenomenon. While Jovicic admits that tourismology does not yet exist, he is optimistic that it "will find its full assertion in the near future" (1998, p.2; in Echtner \& Jamal, 1997, p. 869).

Goeldner (1988; in Tribe, 1997, pp. 642-646) describes tourism as a discipline. He sees it as being in its formative stages on a parallel with business administration as it was developing in the United States about 30years ago. On the other hand, according to Cooper, Fletcher, Gilbert and Wanhill, "While tourism rightly constitutes a domain of study, at the moment it lacks the level of theoretical underpinning which would allow it to become a discipline" (1993,p.1; in Tribe, 1997, pp. 642-646). Perhaps the debate as to whether the study of tourism is a discipline or a field is still unsettled. Hirst proposed a limited number of forms of knowledge or disciplines. He explained the meaning of a form of knowledge, or discipline, as "a distinct way in which our experience becomes structured round the use of accepted public symbols" (1974,p.44; in Tribe, 1997, pp. 642-643).

Tribe (1997), Gunn, (1987) and Jafari and Ritchie (1981) argue that tourism should be treated as a "field" of study. Contrasting fields and disciplines, Henkel noted that disciplines are held together by distinctive constellations of theories, concepts and methods" whereas fields" draw upon all sorts of knowledge that may illuminate them" (1988:188;in Evans, 2012,p.217).

It is accepted that tourism is a field of study rather than a discipline it has a significance consequence. It follows that many different approaches can be applied 
to examine the multi-faceted topic of "tourism"! Mill and Morrison (1985; in Evans, 2012, p.217) first-edition of The Tourism System presented four interconnected parts of the system (market, travel, destination and marketing) showed how one might study the various functions within the systems.

Since its entry into mainstream higher education the study of tourism has attracted debate regarding its disciplinary status and the advantages and disadvantages of various approaches to its understanding. The debate has primarily focused upon the conceptualization of tourism (Franklin \& Ryan, 1999 ; in Evans,2012,p.216) and specifically on whether or not tourism should be treated as a distinct discipline. The articulation of this debate continues to reveal division of opinion (Evans, 2001 ; in Evans, 2012,p.216). On the one hand authors such as Leiper, (1981), Jovicic(1988), Conic (1989) and Rogozinski (1985) have advocated that tourism should be treated as a distinct discipline. Others, on the other hand, maintain that tourism as an area of study fails to meet the necessary criteria. In order to be treated as a distinct discipline (Dann et.al; 1988 ; Echnter \&Jamal, 1997 ;Gunn, 1987 ; Jafari, 1990; Morley, 1990 ;Pearce \& Butler, 1993 ; Ritchie \& Goeldner, 1994 ;Tribe, 1997 ; in Evans, 2012, p. 216)

Traditional disciplinary knowledge is limited in its ability to support the challenging decisions that lie ahead. Global stability in the future will depend upon our ability as a society to simultaneously address the three fundamental issues of prosperity, security and sustainability (Shariq, 1997,p.75).We are entering into an era where the future will be essentially determined by our ability to wisely use knowledge, a precisions global resource that is the embodiment of human intellectual capital and technology (Shariq,1997,p.75).

Based on Hirst's set of necessary characteristics for a discipline, tourism studies cannot be regarded as one for several reasons. First, tourism studies can, in fact, parade a number of concepts. These include, for example, the destination, the tourism multiplier, yield management, tourism impacts, and tourism motivation. But these concepts are hardly particular to tourism studies. They are concepts that have started life elsewhere and been stretched or contextualized to give them a tourism dimension. The tourism multiplier, for instance, borrows the concept of the multiplier developed by economists and uses it to illustrate the extent to which tourism spending stays in a particular region. Second, tourism concepts do not form a distinctive network. They tend to be separate and atomized and indeed need to be understood generally within the logical structure of their provider discipline. They do not link together in any logical way to provide a tourism studies way of analyzing the world. Third, tourism study does not have expressions or statements which are testable against experience using criteria which are particular to tourism studies. 
Leiper registered an enthusiasm for developing tourism as a discipline: to overcome the defects stemming from a fundamentally fragmented curriculum, a new discipline needs to be created to form the core strand in comprehensive programs especially at the professional level (1981; in Tribe, 1997, pp. 642-646). Leiper terms a general tourism theory and argues a system overview. His general tourism theory is based on the articulation of the system as composed of tourist's generating regions, transit routes, destination regions, and the industry. But while this is a useful mapping of the dimensions of tourism, it hardly constitutes a unifying theory of tourism. Leiper further suggests that the term tourology be used to describe the discipline that he sees as developing on the basis of his general tourism theory. It is a "suitable name for the scientific study of tourism". Some 15years after the publication of Leiper's paper, there is no evidence of such a term being used (Tribe, 1997). Leiper (2000, p. 5), advocates that this is necessary because tourism-related phenomena are too complicated, with too many implications, for knowledge to be adequately developed by specialists favoring one discipline (Coles et.al., 2006, p. 298).

Since this article published in the journal, this became impetus for understanding tourism in better way although this theory has been bitterly criticized by Leiper (1981) who while disagreeing with this approach proposed another model that is tourism as tourology or touristology and tourism as discipline. This became a very popular academic debate in between the tourism scholars, researchers and students that brought positive confusion among the readers. Such kind of academic debates are not new in the field of tourism academia. There was same kind of debate in between Bob Brotherton $(1999,2000)$ and Paul Slattery $(2002,2003)$ on hospitality issue. When Brotherton wrote one article on hospitality in 1999 and one year after there came out a seminal book on hospitality edited by Conrad Lashley and A. Morrison in 2000. In 2002, Paul Slattery bitterly criticized on the work of Brotherton and Lashley. This was immediately responded by Brotherton in 2002 and again Slattery (2003) replied to Brotherton and Brotherton (2003) gave final response to Slattery. It is noteworthy to mention that the statement of Mahoney (1993, p.174; as quoted by Taylor and Edger, 1996, p. 212). As Mahoney writes, "Disagreement does not entail disrespect. The main philosophical point, made by Plato and other followers since, is that any criticism is better than a dismissal or an oversight" (1993, p. 174).

In course of making debate on tourism as discipline (Leiper, 1981,2000) or indiscipline (Tribe, 1997) the next debate centralized on tourism is science or not. In the absence of disciplinary status, tourism may turn to science for an appropriate framework. For example, Gunn notes that an important way of "gaining [tourism] knowledge is through science". Gunn sees in science a quality of paramount importance that is its method of "questioning and systematic check" (1987:4; in Tribe, 1997, pp. 646647). Science certainly provides one appropriate epistemology for tourism studies. 
Leiper's (1981; in Tribe, 1997, pp. 646-647) proposed science of tourology makes a similar presupposition to Gunn that tourism studies is a scientific study. This is redolent of the development of economics as a discipline. Economics sought respectability in the rigor of the scientific method. But the effects of developing orthodox economics on scientific and mathematics methodologies have been that first economic theory has increasingly become separate from the phenomenal world that it seeks to describe, and second that phenomenal world is seen in a particular way.

Leiper (1990,p.19; in Echtner, 1997, p. 875), identifies two major, relatively isolated camps in tourism studies: the business-enterprise and development camp (devoted to growth and profit), and the impacts and externalities camp (concerned with effects of tourism on host nations and communities).

No Single discipline alone can accommodate, treat, or understand tourism; it can be studied only if disciplinary boundaries are crossed and if multidisciplinary perspectives are sought and formed. Because many disciplines or fields relate to the study of tourism (Jafari \& Ritchie, 1981), the scope of this special issue had to be defined and carefully designed at the outset in order to ensure the thematic treatment. Since tourism is, foremost, a socioeconomic phenomenon and an institution in its own right, and since social science have collectively made significant contributions to its study, Tourism Social Science was selected as the theme. This theme is developed here by utilizing the basic building blocks of anthropology, economics, geography, and more. Papers on such fields as ecology and marketing-because their present research on tourism is greatly influenced by social science theories and methodswere also solicited for a fuller thematic development (Graburn \& Jafari , 1991, pp.7-8).

As to development of this special Issue, in July 1986, twenty editors (two for each article) were invited to contribute. The invitation letters gave "Tourism Social Science" as the theme, described the purposes, delineated the thematic components, and gave the time table. The potential authors were informed on the contexts and flow of the papers:

First, ...to define the field assigned to [each paper] but also elaborating on its main concerns, methods of investigation, boundaries with/or linkage to other fields.... Second, to place tourism in the context of the assigned field, to examine its application to tourism....Third, to discuss other application of and contributions from the field to the study of tourism..... Fourth, to tie together all that has been discussed... A retrospective view should lead to a prospective commentary which sheds light on and guides the reader to uncharted explorations in that field. Finally, to have at least twenty-five contextualized references...representing the best contributions that the discipline has made to the study of tourism (Graburn, 1991, p.8). 
The Special issue's ten disciplinary articles on tourism- and anthropology, ecology, economics, geography, history, leisure/recreation , marketing, management, political science, psychology, and sociology - together contain the breadth, depth, richness, and potential that one can expect at this early stage in the formation of knowledge in the field of tourism research. The two editors ( Nelson Graburn and Jafar Jafari, 1991, p.9).

\section{Tourism as a Field}

Hirst $(1965,1993$; in Tribe,1997) has also turned his attention to the notion of fields of knowledge. These are not, in his view, disciplines or subdivisions of disciplines. This is because a field does not have the coherence of a discipline. In a sense fields and disciplines relate to the phenomenological world in different ways. A discipline provides a particular tool kit in terms of concepts, acquired knowledge, and methodology, and this tool kit is used to illuminate a particular part of the external world. A pair of disciplinary spectacles is provided by a discipline, and these spectacles reveal particular truths about the world. Thus, a physicist would see the external world in a particular way. For example, a physicist's interest in the world of tourism might include aspects such as the reasons that aircraft fly, using concepts such as aerodynamics and lift (Tribe, 1997, pp. 647-648).

Fields work from the opposite direction. Fields are formed by concentrating on particular phenomena or practices such as tourism or housing or engineering. They then call on a number of disciplines to investigate and explain their area of interest. Knowledge flows in different directions between fields and disciplines. Henkel contrasted disciplines which "are held together by distinctive constellations of theories, concepts, and methods" with fields which "draw upon all sorts of knowledge that may illuminate them" (1988,p.185; in Tribe, 1997, pp. 647-648).

Several writers have considered tourism as a field as depicted by the above definitions. Gunn lists the main disciplines that he sees as contributing to tourism as marketing, geography, anthropology, behavior, business, human ecology, history, political science, planning and design, and futurism. Futurism is defined as "applied history" and results when "philosophers, scientists, technicians and planners have joined in making insightful studies of trends" (1987, p.8; in Tribe, 1997, pp. 647-648).

According to Gunn, "Tourism knowledge today is building through a variety of means...First tourism practitioners know certain things because of tenacity...second is the method of authority...A third way of gaining tourism knowledge is by means of intuition...The fourth way of gaining knowledge is through science" (1987,p.4; in Tribe, 1997, pp. 647-648).

Jafari and Ritchie (1981, p.23) presented a model of tourism studies as a field. They believed that their model helps to illustrate the multidisciplinary nature of tourism studies. 
Sourece: Tribe 1997, p. 650.

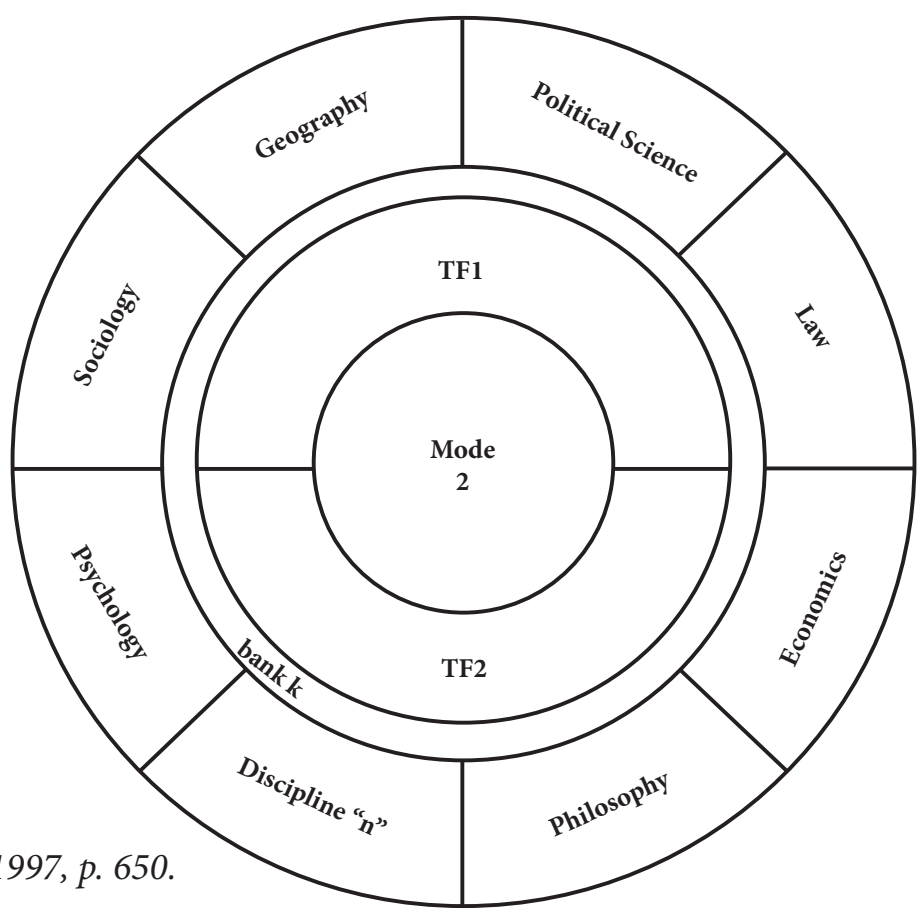

Figure: The Creation of Tourism Knowledge. Outer Circle=Disciplines and Subdisciplines; Middle Circle=Fields of Tourism; Inner Circle=World of Tourism; TFl =Business Interdisciplinarity; TFZ=Non-Business-Related Tourism

One field is readily identifiable as tourism business studies. The identity of this is borrowed from the increasingly mature field of business studies which has now tentatively carved out a particular territory as its own. Tourism business studies shares a similar territory to business studies but in a tourism context. It includes the marketing of tourism, tourism corporate strategy, tourism law, and the management of tourism.

The other field of tourism studies does not have such an obvious title, because it is little more than just the rest of tourism studies (or non-business tourism studies), is less obviously purposeful than tourism business studies, more atomized, and lacking in any unifying framework other than the link with tourism. It includes areas such as environmental impacts, tourism perceptions, carrying capacity, and social impacts. This may be called tourism field two (TF2), using TFl to denote tourism business studies. Therefore, the field of tourism $(\mathrm{TF})=\mathrm{TFl}+\mathrm{TF} 2$. However, it should be noted that there is some overlap between the two. Concepts such as environmental impacts of tourism development reside essentially in TF2, but since they indirectly affect the business of tourism they also overlap into TFl (Tribe, 1997, p. 649; Obenour. Lengfelder \& Cuneen,2005,pp.44-45). 
Concerning epistemology, building on prior reflections of Jafari and Ritchie (1981), Tribe (1997) presented a model of tourism studies, to be precise, actually distinguishing two quite separate field of tourism studies: tourism business studies and non-business tourism studies (tourism social science). According to Tribe, these two fields build a medium layer of tourism knowledge creation, encompassed by established disciplines (philosophy, geography, economics, sociology, etc.) In this context, Tribe implicitly identified two cores of tourism knowledge production: a so-called 'band k' characterized by 'model' (academic knowledge production), and a 'mode2', which covers tourism knowledge production taking place in tourism practice, mainly in the business of tourism (see also Gibbons et al., 1994;Nowotny et al.,2001; in Volgger \& Pechlaner, 2015,p.90).

In the first core, 'band k', the study of tourism interacts with traditional disciplines. It is here 'where tourism theories and concept are distilled' and 'where tourism knowledge is created' (Tribe, 1997,p.650). In particular, Tribe (1997) describes the nature of knowledge production in this first core as often being as multi-disciplinary and interdisciplinary, the latter being true especially for the subfield of tourism business studies ('business interdisciplinarity'). In contrast, so-called 'mode2' knowledge production takes place outside the disciplines in the practical world. Therefore, according to Tribe, it could be called transdisciplinary or extradisciplinary knowledge production. Tribe describes tourism as a field of knowledge which calls upon a number of disciplines to investigate and explain their area of interest and quoting Hirst (1965, p.130), he describes fields as being ' formed by building together round specific objects or phenomena, or practical pursuits, knowledge that is characteristically rooted elsewhere in more than one discipline' (Tribe, 1997,2000,p.287). This immediately positions fields of study like tourism and hospitality management as multidisciplinary in origin in that they draw upon more than one discipline. But also they are potentially interdisciplinary in that they can serve as a focal point in which disciplines can come together to present new insight or new knowledge. This provides the basis for Tribe, drawing upon the work of Gibbons et al. (1994;in Tribe 1997,2000), to identify the areas where knowledge about tourism is developed: in the contributing disciplines themselves and in the interdisciplinary areas where two or more disciplines come together. Interdisciplinary education fosters the development of all three components of "successful intelligence" covering creative intelligence, analytical intelligence and practical intelligence (Repko, 2012, p.39). Creative intelligence is required to formulate ideas and solutions to the problems. Analytical intelligence is required to solve problems and to evaluate the quality of ideas. Practical intelligence is needed to apply the ideas in effective way, whether in business or in everyday life. What makes for successful intelligence, says Sternberg, is balance among these three ways of thinking. It means knowing how 
and when to use these aspects of successful intelligence rather than just having them (Sternberg, 1996 ,p.128;in Repko,2012,p.39). Interdisciplinary education fosters the development of all three components of "successful intelligence"(Sternberg, 1996 ,p.128;in Repko,2012,p.39).

Tribe also identifies second area of knowledge generation which he labels extradisciplinary knowledge. Tribe describes tourism as a field of knowledge which calls upon a number of disciplines to investigate and explain their area of interest and quoting Hirst (1965, p.130 ; in Tribe, 2000) he describes fields as being 'formed by building together round specific objects or phenomena, or practical pursuits, knowledge that is characteristically rooted elsewhere in more than one discipline' (in Tribe 1997, 2000, p.287). This immediately positions fields of study like tourism and hospitality management as multidisciplinary in origin in that they draw upon more than one discipline. But also they are potentially interdisciplinary in that they can serve as a focal point in which disciplines can come together to present new insight or new knowledge. This provides the basis for Tribe, drawing upon the work of Gibbons et al. (1994), to identify the areas where knowledge about tourism is developed: in the contributing disciplines themselves and in the interdisciplinary areas where two or more disciplines come together.

Tourism 'does not recognize disciplinary demarcations, no matter how distinct the disciplinary boundaries might seem to be. Its concerns, more often than not, cross disciplinary boundaries and find themselves home' (Jafari \& Ritchie, 1981, p.22). Starting from the assumed consensus that TH\&E research and education require combining a range of traditional disciplines, the question that arises is how to combine them. In this regard, Volgger and Pechlanar $(2015, \mathrm{p} .87)$ propose four main approaches to such disciplinary combinations below.

Gibbons et al. (1994) started to make a distinction between Mode 1 and Mode 2 knowledge productions. On the one hand, Mode 1 knowledge refers to the traditional academic, decontextualized debates among members of universities according to universal rules and procedures. Natural science at traditional universities is the most appealing example of this type of knowledge. Mode 2, on the other hand, implies the changing context of application in which different teams of researchers collaborate in transient environments. Tribes and Portegies et al. ( 2009, p.84; in Issac,2013 ,p.94) used this distinction in the area of tourism studies. Coles et al.(2009,p.84) say that "Mode 1 appears to be the dominant type of higher education these days, as the traditional centre of knowledge production', whereas Mode 2 was originally anticipated as taking place outside university structures “. Gibbons et al.(1994), Tribe (1997), Lengkeek and Platenkamp (2004) and Platenkamp (2007) have introduced an extra mode of knowledge apart from the academic one that we know since the end of $17^{\text {th }}$ century ( Portegise et al.,2009,p.527). Mode 3 knowledge has been introduced 
by Kunneman (2005; in Issac, 2013,94)- normative and existential knowledge- in the awareness that in both of the other Modes- in the professional as well as in the academic knowledge productions (Gibbons et al, 1994; in Isaas, 2013,p.94)- there is a long-term tendency to exclude the "slow questions' (Kunneman, 2005, pp.116-123; In Isaac, 2013,p.94). These "slow questions' are in contrast with 'quick questions' that emerge from everyday reality. They do not require quick answers because they are dealing with universal concerns related to sickness, death, repression and in addition " moral virtues as compassion, inner strengths or wisdom, and other sources of existential fulfilment that remain crucial for all generations in various places and space" (Issac et al., 2012,p.162). According to Issac and Platencamp (2012,p.178; in Issac,2013,p.94), there are two ways of tourism knowledge production associated with Mode 2 which lead to the objectifying knowledge of Mode 1, and on the other, the existentially and morally-laden values that are co-determinant for organizing these solutions in Mode 3. Knowledge production in Mode 3 is linked to the powerful character of these values and frames of meaningful interpretations of the questions and problems in the context of application in Mode 2.

\section{Lifelong Learning}

The first Tourism Education Future Initiative (TEFI) Conference at Module University Vienna explored various futuristic scenarios of the society to which tourism education programmes would need to adapt. Modifying tourism education programmes to fit a multitude of possible world scenarios, or even a single preferred scenario was found to be task fraught with too much specificity and uncertainty. At the second TEFI Conference at University of Hawaii, USA, Five values-based principles were defined so that they can be fully integrated into tourism education programs. So as to ensure that students become responsible leaders and stewards for destination.

There are three worlds of TEFI Values : The Ideal Tourism World, The Real Industry World and Tourism Higher Education (over all three tourism world). All these three worlds of values are interdependent and focused on knowledge; ethics; professionalism; mutuality; and stewardship (Mihalic, Liburd \& Guia , 2015 , pp. 47 58 ). They are conceptually portrayed as inter-locking value principles demonstrating their inter-connectedness and permeability. TEFI members envisioned that educators can use subsets of the five value principles to integrate into their courses as appropriate (Sheldon \& Fesenmaier, 2015, pp.156-157

Human learning passes through various stages (e.g. Novice, beginner, performer, competent performer, expert) and there is a development leap between the rule-bound knowledge demonstrated by experts (Bordier, 1997; Dreyfus \& Dreyfus, 1986; in Dredge et al., 2012, p.2159). This learning requires critical and reflective engagement 
with troublesome knowledge and may involve life-long learning well beyond a three year undergraduate curriculum (Meyer \& Land, 2003, 2005; in Dredge et al.,2012, p. 2159).

Lifelong learning has been characterized as a lifelong and life-wide process (Falk et.al, 2012; in Su, 2015, p.323) that extends the time period of tourism education at all levels (Cuffy et al., 2012; in sSu, 2015, p323). In addition, lifelong learning also refers to learning in a wide variety of settings, including formal (e.g., a university education program), non-formal (in service training, certification) informal learning settings (e.g., travel, reading) (Su, 2015, p.323).

The lifelong learning perspective proposes a model of four learning pillars, an idea from the Delors Report (Delors, 1996; International Commission on Education for the twenty first century, 1996), for sustaining tourism employment in the face of the dynamic changes in the tourism world. This model is a conceptual framework for tourism curriculum that can ensure graduates' continuity of knowledge, competencies and other skills that can change with the changing demands of the tourism industry and can improve and broaden tourism development. In this framework, lifelong learning is based on four- learning pillars i.e. Learning to know, learning to do, learning to live together and learning to be -that are key for growth and developmentin today's knowledge-driven, twenty first century societies. (Su, 2015, p.324).

One can think of tourism education as developing lifelong learning capacities in graduates, which help them not only to meet industry demands but also to live within a larger natural or social environment that is inevitably influenced by, and can influence, tourism. These pillars emphasize the connection between the learners and society while synthesizing knowledge about commercial and non-commercial tourism as well as the vocational and the liberal education (Tribe, 1997, 2002a, 2005; in $\mathrm{Su}, 2015$ p.325):

1. Learning to know: The ability to learn to construct, change and renew tourism knowledge in scope with the changing tourism industry. These abilities, presented in a non-exhaustive, include learning to understand, to use computer technology, to search for and integrated information, to analyze, to reason and think critically, to learn in a boarder, liberal context and beyond disciplines, and to create.

2. Learning to do: Not only the ability to apply knowledge and skills and to operate and practice them in occupational contexts but also to adapt and be flexible, to solve problems, and to participate in tourism renovation and change with broader social and environmental interests in mind.

3. Learning to live together: The ability to communicate orally and trough writing, to work collaboratively and lead groups, to be sensitive to customers 
and individuals from different cultures, and to listen to, respect and express concern for larger social and environmental needs and benefits.

4. Learning to be: Development of the will to learn, to be curious and openminded, to take initiative, to manage oneself, to find self-worth and meaning, and to be confident in being engaged with and making contributions to tourism and non-tourism contexts ( $\mathrm{Su}, 2015, \mathrm{p} .325)$.

Following the global trend in lifelong learning, tourism employers are increasingly more concerned with generic attributes that make graduates flexible and adaptable to change. Tourism employers value graduates' capabilities for communication, problem solving, working with others and self-management (Lopez-Bonilla \& Lopez-Bonilla, 2012; in Su,2015,p.324). As Su (2015) positively contends "We may need to think of tourism education as developing lifelong learning capacities in graduates, which help them not only to meet industry demands but also to live within larger natural or social environment that is inevitably influenced by, and can influence, tourism". (pp.324-325).

Kolb's experiential learning theory is another instrument of tourism education process. According to Kolb, experiential leaning is "The process whereby Knowledge is created through the transformation of experience." And "Knowledge results from the combination of grasping and transforming experience." Kolb's experiential learning model involves four phases: Starting from the concrete experience phase a student goes through, followed by the reflective observation phase and the abstract conceptualization phase, finally round up his learning in the active experimentation phase. Thus, he states that experiential learning occurs on the basis of relevant experience through reflective process (1984, p.4; in Čavlek, 2015, pp.104-105). Kolb's experiential learning theory and some another scholar's research have discovered the value in learning by doing, active learning and applied learning (Deway, 1997, in Čavlek, 2015, p.104).

\section{Inquiry-based learning}

Inquiry-based learning has been recognized as one of the most important method of learning instruments, no matter it is either in the class or in the field. The students might get chance to directly interact with their instructors.

Inquiry can be defined as the seeking for truth, information, or knowledge, seeking information's by questioning. Inquiry-based learning can be described as a range of philosophical, curricular, and pedagogical approaches to teaching. It points out that learning should be based on questions and requires students to work independently to solve problem. Instructors are seen as facilitators of learning, and not people who give right answers and instruction to learners (Jonker, 2014; in Ritalahti, 2015, p.138).

The idea of inquiry (-based) learning is actually quite old. According to Jonker 
(2014; in Ritalahti, 2015, p.138), inquiry-based learning is an instructional method that was developed in the 1960s. He thought that inquiry learning is a form of active learning where the students' progress is measured or assessed by their development in the process. It is about experimental and analytical skills instead of knowledge processing. Inquiry-based learning is a student-focused and students-led process that aims to engage students in active learning (Bishop et al., 2004). Basically when the students are in the field, they themselves seem to be motivated to ask the questions to their instructors.

Inquiry or inquiry-based learning can be described as a project-oriented pedagogic strategy that is based on constructivist and socio-constructivist theories of learning(Eick and Reed, 2002). This learning model is collaborative work, work that is done in a group or groups. Work in this frame work includes talking, work-sharing, and using different tools to create knowledge. Inquiry-based learning encourages students to learn through engaging them with challenges ( Ritalahti, 2015, pp.138139).

Inquiry-based learning emphasizes the complex, multi connected nature of knowledge construction, aiming to provide opportunities for both teachers and students to work together and collaboratively build, test, and reflect also on their own learning. The challenge of implementing inquiry-based learning is many. Edelson et al. (1999, pp. 399-400; in Ritalahti, 2015, p.140) pointed out five challenges: motivations, accessibility of investigation techniques, background knowledge, management of extended activities, and the practical constraint of the learning context. Students who are involved in inquiry learning must be motivated.

\section{Disciplinary Pluralism}

They are Henry (1987), Kellert (2008) and Lusiani and Zan (2013, Notes 1,p.113) who popularized the concept of disciplinary pluralism. A very comprehensive definition of discipline among the available literature is of William Bechtel's overview that delineates discipline as can be identified by their objects of study (domains ; phenomena), by their cognitive tools (theories, techniques), or by their social structure (Turf, Journals) (Bechtel, 1987.p.297; Hayles, 1990,p.191; in Kellert, 2008,p.29). Similarly, the word pluralism in case of discipline follows various connotations as synonymous of and used interchangeably with the term multidisciplinary, interdisciplinary and transdisciplinary. In align with these propositions, disciplinary pluralism is or invites the use of techniques from multiple disciplines to understand the subject matter of an investigation which may be used by one investigator, by a team of researchers or by a number of individuals or teams (Kellert 2008,p.28). Kellert (2008) has proposed two main features disciplinary pluralism, that is, using a wide array of techniques of enquiry, and normative 
naturalism, that is, using empirical enquires to inform evaluative judgements about what works well and what does not (p.25). One may ask questions about the social structures of academic work, the way language works, and the nature of evaluative questions... disciplinary pluralism that is, using a wide array of techniques of inquiry (Kellert, 2008).

Disciplinary pluralism is ultimately a feature of a community of enquirers- a community that this work seeks to inaugurate (Kellert, 2008, p.55). Following Henry (1987, p.280) who asserts that a plurality of different models can be identified and each has its own particular brand of individualized soul- training and instrumental objectives which depend in part on the view each model takes of human nature and social order, it may, then be useful here to refer to some of the disciplines which may lend their theories and techniques to the study of tourism.

Echtner and Jamal (1997), in a wide ranging review of the "disciplinary dilemma" of tourism studies, argued that the knowledge-based platform is consistent with the more toward the treatment of tourism as a distinctive discipline. However, in order to reach such a position, these authors advocate that tourism needs to overcome its theoretical fragmentation and research has to move towards an interdisciplinary (as opposed to a multidisciplinary) approach (Evans, 2012, p. 216).

Taking about pluralism and tourism, an important question here is then: how does disciplinary pluralism fit in case of tourism? State it differently, has tourism got its own objects of study and cognitive tools and theories within particular social structure for the same? This brings us in our consideration the understanding of the evolutionary process of tourism which is tied up with an ongoing scholastic debate on whether tourism is a separate discipline or just an entity within social sciences such as sociology, anthropology, economics, geography and psychology helps us to understand disciplinary pluralism within the context of tourism as a discipline. Moreover, it may be equally important to refer to some of the tourism concerns that might be studied within the context of these disciplines.

Traditionally, each discipline having an interest in tourism has focused on one or more particular aspects or functioning of the total system (Ritchie \& Johnston, 1978). Many disciplines which have their share on tourism provide useful ways to understand and evaluate the phenomenon of borrowing.

Tracing the evolutionary trajectory of tourism, Jafari (1990) writes four tourism platforms (Advocacy, Cautionary, Adaptancy and Knowledge-based Platforms) that emerged chronologically but without replacing one another. The first two platforms focus on tourism impacts and the third one forms of development. The last, the Knowledge-based Platform, aims to study tourism as a whole and strives for the formation of a scientific body of knowledge in tourism, while "maintaining bridges 
with other platforms" (1990, p. 35). He believed that a cross-disciplinary approach was justified in creating knowledge based approach to the teaching of tourism, but argued that tourism education should continue to be rooted in established disciplines. It is evident that the objectives of the Knowledge-based Platform are consistent with a move toward tourism as a distinct discipline (Echtner, 1997, p. 879).As tourism discourse progressed into the twenty-first century, Macbeth (2005) suggested extending Jafari's ideal model and introduced a fifth platform of tourism through: the 'ethical' platform. Macbeth had also called for a sixth platform of tourism thought, intended to oppose the positivistic scientific paradigm which views knowledge as objective and all-knowable (Macbeth, 2005; in Boyle, Wilson \& Dimmock, 2015, p. 521).This growth of tourism studies has been helping to reshape such boundaries, as well as being influenced by them.

The important question is whether the field of tourism studies is in good health. The answer is of course contingent. It could be argued that the high level of research activity implies that it is in excellent health and has become solidly institutionalized in the academy. Yet, the field has also been substantially criticized in term of its theoretical based. As Meethan (2001:2; in Hall et al., 2005, p. 14) commented, "for all the evident expansion of journals, books and conferences specifically devoted to tourism, at a general analytical level it remain under-theorized, eclectic and desperate." The comments of Franklin and Crang (2001,p.5; in Hall et al., 2005, p. 14) are similarly astringent:

The first trouble with tourism studies, and paradoxically also one of its sources of interest, each that its research object, "tourism," has grown very dramatically and quickly and that the tourism research community is relatively new. Indeed at times it has been unclear which was growing more rapidly-tourism or tourism research. Part of this trouble is that tourist studies have simply tried to track and record this staggering expansion, producing an enormous record of instances, case studies and variations. One of the reasons for this is that tourists studies has been dominated by policy led and industry sponsored work so the analysis tends to internalize industry led priorities and perspectives...Part of this trouble is also that this effort has been made by people whose disciplinary origins do not include the tools necessary to analyze and theorize the complex cultural and social processes that have unfolded (Hall et al., 2005, p. 14).Echtner and Jamal (1997, p.879) also stressed that to be “...Liberalism with regard to methodological approach and concurrently greater attention to clearly explicated theory and methodology".

Tribe's (1997,2010,p.10) analysis under this context established criteria to settle the question of disciplinarity status and concluded that tourism studies were unable to pass the test. Rather it was found to be a field or more specifically, two fields of study, labelled TF1 (The Business of Tourism) and TF2 (Non-Business related 
Tourism).Knowledge creation occurred, according to Tribe, by multidisciplinary, interdisciplinary and extra-disciplinary efforts. Here extra-disciplinary knowledge means which is pulled from the complexity of the problem being studied rather than pushed from the prevailing disciplines (Tribe , 2010, p.10). In this regard, Bodewes (1981: 37; in Hall, Williams \& Lew, 2005, p. 7) argued that "tourism is usually viewed as an application of established disciplines, because it does not possess sufficient doctrine to be classified as a full-fledged academic discipline."

Contrarily Pearce (1993) argued "simply because the tourism field in the 1990s is classified as soft, rural, pre-paradigmatic and specialist does not mean we cannot make progress towards cumulative, cross-situational generalities" (1993:29; in Echtner, 1997, p. 880). There are some indications that tourism is moving toward becoming a distinct discipline. A multidisciplinary approach involves studying a topic by including information from other disciplines, but still operating from within disciplinary boundaries. Similarly, an interdisciplinary focus involves "working between the disciplines", blending various philosophies and techniques so that the particular disciplines do not stand apart but are brought together intentionally and explicitly to seek a synthesis “ (Leiper,1981,p.72;Nikitina,2015,pp.413-414; in Repko,2012,p.19).

Interdisciplinary research on tourism can be defined as the organization of an interface between different disciplines and bodies of knowledge in order to analyze the manifestations and the existing complexities of society's touristic dimensions. Interdisciplinary research involves organized coordination within a research process. Interdisciplinarity is a process of hybridization through 'nomadism', i.e. circulation of concepts and practices. Hannam (2009; in Tribe, 2010, p.10) suggests the replacement of tourism studies by nomadology and the mobilities paradigm. Nomadology describes an even more radical deterritorialization of the academic where as Deluze and Guttari (1988, p.52; in Tribes, 2010, p.11) note "the nomad had no point, paths or land."

This is another reason why tourism studies can neither be a paradigm nor an autonomous 'field of study' (Lehre, e'tudes, studies) nor a unified science (Wissenschaft,science) as 'tourism ology': as a research object, which multiple relationships with other elements of society, it gives the illusion of the possibility of an integrated field. The construction of a common vocabulary, despite the limitations of the different disciplinary perspectives, is one of interdisciplinary work's key issues. It is an open question whether it is possible to integrate the political science's 'governance' and 'institutional resource regime', geography's 'centrality', anthropology's 'culture', economics' 'capital investment', sociology's 'distinction', marketing's 'image' etc. in one coherent description and explanation of tourism (Stock, Clivaz, Crevoiser. Darbellay, \& Nahrath, 2011; in Darbellay \& Stock,2012, pp. 454-455). 
In this regard, Echtner and Jamal (1997) questioned where would such a discipline be housed? Since many of the disciplines currently studying tourism fall within the social sciences (sociology, anthropology, economics, geography, psychology), should a discipline of tourism studies be located within the faculty of social sciences? ( pp. 879-880) It is evident, from both a philosophical and a practical perspective, that the development of tourism as a distinct discipline is not a certainty. A greater degree of collaboration across disciplines is required at this point to further advance the study of tourism towards a distinct discipline ( Echtner \& Jamal, 1997, p. 880).However, while tourism studies could potentially develop into a discipline, it is concluded that there are many practical and philosophical reasons that hamper its evolution. What is urgently needed is greater collaboration, cross-disciplinary \& especially interdisciplinary research (Echtner\& Jamal, 1997, pp. 880-881).The organization of tourism as episteme leads to a specific cognitive project in which the touristic dimensions of society, not tourism as an autonomous system, is at the core of interdisciplinary approaches (Darbellay \& Stock, 2011, p.455).

The scholars of tourism are also concerned with transdisciplinary approach and have argued its essentiality or alternative. Transdisciplinarity refers to the explicit abandonment of disciplinary boundaries. Indeed, Tribe (1997) collates the term extradisciplinary to transdisciplinary in order to denote the creation of knowledge outside existing disciplines, by resorting to practical sources. Transdisciplinarity involves contesting established places (institutions) of knowledge production, thus replacing the knowledge privilege of science with a more heterarchic open space of knowledge production. Nowotny et al. (2001;in Volgger \& Pechlaner,2015,p.88) refer to this space with the metaphor of the ancient agora. Transdisciplinarity approaches start with problems (Jafari\& Ritchie, 1981) and develop specific theoretical bases, methods and implementations that are not reducible to an already existing discipline (see Gibbons et al., 1994;in Volgger \& Pechlaner,2015,p.88). [T] transdisciplinarity contributes to a joint problem solving that it is more than juxtaposition; more than laying one discipline alongside another... If joint problem solving is the aim, then the means must provide for an integration of perspectives in the identification, formulation and resolution of what has to become a shared problem (Nowotny, 2003, p. 1.; in Volgger \& Pechlaner, 2015, p. 89).

As discussed in earlier sections, Tribe (1997 identifies a second area of knowledge generation which he labels extradisciplinary knowledge. He quotes Gibbons et al. (1994, p.vii) to explain that extradisciplinary knowledge. . . operates within a context of application in that problems are not set within a disciplinary framework ... It is not being institutionalised primarily within university structures . . . [and] makes use of a wider range of criteria in judging quality control. Much of this form of extradisciplinary knowledge for tourism, according to Tribe, is generated 
not in higher education but in the business world and the sites of such knowledge production include industry, government, think tanks, interest groups, research institutes and consultancies (1999, p.103; in Airey \& Tribe, 2000, p.288). He gives examples of such knowledge production in tourism as including 'developments and applications of information technology for tourism such as smart hotel rooms, yield management systems and computerized reservation developments- developed in the industry for the industry ' (1999, p.103; in Airey \& Tribe, 2000, p.288). He concludes on this point: The important points to note about [this] knowledge production are first that it occurs outside higher education, the traditional centre for knowledge production. Second that is it developing its own epistemology.... [This] knowledge ... judges its success by its ability to solve a particular problem, its cost effectiveness and its ability to establish competitive advantage that is its effectiveness in the real world. In many ways Tribe's comments about multidisciplinary, interdisciplinary and extradisciplinary knowledge generation can be related to a wide range of fields of study. For example housing, media studies, leisure management as well as hospitality management all demonstrate similarities with tourism (Airey \& Tribe, 2000, p. 288).

The case for postdisciplinary enquiry in tourism studies following the pioneer groundwork of Coles et al.(2006). Postdisciplinarity (or supradisciplinarity) is described as a perspective that contests disciplines and other academic demarcations questioning their content, nature and exclusiveness (Beier\& Arnold, 2005). Coles et al.(2006) have endorsed the view of Visnovsky and Bianchi (2005: no pages), the editors of Human Affairs: A Postdisciplinary Journal for Humanities \& Social Sciences, who argue: Postdisciplinarity in our understanding does not mean that the traditional disciplines have disappeared or indeed should disappear, but rather that they are changing and should change in order to solve complex issues of human affairs. It is not sufficient to approach such complex issues from any single discipline (p. 312). This theory has been advanced by Keith Hollinshead in two short manuscripts on the subject. In the first, an article in Tourism Analysis, Hollinshead (2010), makes the case that postdisciplinary enquiry is a field of scholarship that is notably useful in tourism settings and scenarios... and another a chapter in the Routledge publication The Critical Turn in Tourism Studies- Hollinshead (2012) attempts to show how recent advances in the soft science... fertilize the conceptual ground upon which postdisciplinary thought operates (Hollinshead \& Ivanova,2013,p.56).

According to Hollinshead, the postdisciplinary studies are: forms of systematic or exhaustive longitudinal (through time) and latitudinal (through place) critique which utilize scholarly and non-scholarly reasoning to map the multiple truths which exist in a found context- or setting and which pay distinct attention to emic/ local grounded understandings which have significant communal, public and 
or claimed longstanding inheritances or otherwise upon emergent and dynamic projections of being or becoming. Such forms of critic tend to serve as dialectical open-to-the-future inspections which uncover and account for the plurality of important (i.e., well supported) outlooks which have been overlooked, ignored, or suppressed either historically (or which being subjugated in the present) by dominant authorities/dominant cognitions (Hollinshead,2012,p.64; in Hollinshead \& Ivanova,2013,p.57).

'The term "postdisciplinarity" evokes an intellectual universe in which we inhabit the ruins of outmoded disciplinary structures, mediating between our nostalgia for this lost unity and our excitement at the Intellectual freedom its demise can offer us'. In other words: whereas transdisciplinarity challenges established 'real' places of knowledge production (academia), postdisciplinarity rather questions the 'metaphorical' spatialization of knowledge production and delivery (division of knowledge in disciplines, etc.).Second homes, crisis/security, identity and the various instances of health tourism are sometimes proposed as candidates for postdisciplinary accounts (Beier\& Arnold, 2005; Coles et al., 2006; Hollinshead, 2010; Ritchie, 2008).

Postdisciplinary knowledge production rejects the 'parochialism and policing' of disciplines (Coles et al., 2006: 305) as well as the 'artificial division of academic labour' (Goodwin, 2004:65). However, postdisciplinary does not mean that traditional disciplines have disappeared, it simply wants purposely to acknowledge diversity by adding a flexible, network and problem-centered approach to existing epistemologies and ontologies (Coles et al., 2006; Hollinshed, 2010).

According to Cole et al. (2006), postdisciplinary approaches offer considerable additional and as yet unrecognized potentials for studies of tourism 'beyond disciplines' particularly with respect to many of the complex, multiscalar issues, such as security, sustainability, mobilities and networks. They argue that the advantage of post disciplinary outlook is that are able to deal with the current issues and challenges of tourism; that is, the complexity, messiness, unpredictability, hybridity of the contemporary world in which tourism takes place and which tourism reflexity helps to mediate (Coles et al., 2006, p. 313).

Some interdisciplinarians, though, share an antidisciplinary view preferring a more "open" understanding of "knowledge" and "evidence" that would include " lived experience", testimonials, oral traditions and interpretation of those traditions by elders (Vickens, 1998,pp.23-26;in Repko,2012,p.53). However, there is a problem with this approach. Without some grounding in the disciplines relevant to problems, borrowing risks becoming indiscriminate and the result rendered suspect (Repko, 2012, p.53). 


\section{Conclusion}

It could be concluded that, in recent decades, an increasing number of social scientists have simply expressed the view that large range of major social, cultural, economic, political and other problematics- such as poverty reduction, migration/immigration, environmental care, ecological stewardship, neo-colonialism/ neo-imperialism and terrorism- are not really, or easily, understood and dealt with via the outlook of any single discipline (Becher, 1989 ; in Hollinshead \& Ivanova, 2013,p.53). The hard scientists (quantitative experts), soft scientists (qualitative experts) and special scientists (specialized in particular areas) have realized the existing problems and explored new territories of understanding knowledge beyond the existing academic disciplines such as disciplinary pluralism ( pluri-discipline, cross-discipline, super-discipline, supra-discipline, meta-discipline, adamantine discipline) instead of uni-discipline.

Cooper and Shepherd (1997) who have highlighted the importance of tourism education in this 21 st century. While following the different approaches of tourism scholars they write, tourism education has a pivotal role to play in facilitating the paradigm shift from the passive to the transformative. As such the role of tourism education has to be realigned to drive the transformative agenda. Various approaches to tourism education has been proposed over the year emphasizing a vocational; liberal or combined agenda depending on the context- These approaches revolve around the four strands of higher education: student- centered approach (Cooper \& Shepherd,1997,p.35) , a work-centered approach (McIntosh,1992; in Lewis-Cameron,2015,p.88), a society-centered approach ( Go,1994, p. 331; in LewisCameron,2015,p.88)) and a balanced approach (Pring, 1995; Burke, Hawkins \& Schulman, 1990,p.685; in Lewis-Cameron,2015,p.89). They view that there is balanced between theory, knowledge and practical skills.

The methodology-driven differentiation of the field is based on the qualitative distinction, the difference between case studies and econometric studies, and the opposition between 'grounded theory' and the hypothetical-deductive style of scientific investigation. This leads to what Echtner and Jamal (1997, p.879) call the 'disciplinary dilemma' they state that an 'evolution of tourism toward increased credibility as a field of study and towards disciplinary status include: holistic; integrated research; the generation of a theoretical body of knowledge; an inter-disciplinary focus; clearly explicated theory and methodology; and the application of qualitative and quantitative methods; positivist and non-positivist traditions' (Darbellay \& Stock, 2012, p. 451).

Disciplines and fields of study change over time, and areas of specialization come and go depending on intrinsic and extrinsic factors. For example, issues such 
as "sustainability" or "safety and security" rise or fall on the tourism agenda of academics, as well as governments, in response to external factors such as terrorism or environmental concerns, as well as on the availability of specific funding opportunities (Hall et al., 2005, p.14).

Across the globe, the tourism industry has also been subject to sustained pressure as a result of concerns over, for example, climate change, terrorism, global financial conditions, environmental crises and health alerts. The tourism industry continues to call for a better skilled and more innovative workforce. Reflecting upon these pressures, this paper builds upon the Philosophic Practitioner Education by incorporating the dynamic lifelong learning element that is inherent in professional practice. The conceptual model developed by Dredge et al. (2012) incorporates the idea of a progressive learner, mindfully engaged in the stewardship of societal change over time (Dredge et al., 2012, p. 2162).

Tourism is not a discipline and is not one but two distinct field. But this distinction between fields and disciplines merely suggests that one is witnessing an object of study (field) rather than a way of studying (discipline). Therefore, one needs to understand how the field of tourism is studied. Tribe's theory attests to the complex epistemologies associated with tourism studies which result in four main methods of inquiry: multidisciplinarity, interdisciplinarity, business interdisciplinarity, and mode 2 (extradisciplinarity). These methods distinguish between those approaches which reside essentially in the world of thought (band $\mathrm{k}$ ) and those which reside in the world of practice (mode 2; Tribe, 1997, p. 653). The other methods of enquiry as mentioned above are also equally important in their places. There is ongoing discussion about 'tourism science ', as a 'discipline' or as a 'field of study'. This was the major issues between N.Leiper and John Tribe.

\section{Acknowledgements}

I would like to express my sincere thanks to Uttam Bhattarai and Neeru Karki of Nepal Mountain Academy. My equal thanks goes to Rajan Rai of Department of Conflict, Peace and Development Studies, Tribhuvan University and Amir Bharati of GATE College who helped me in setting this paper. My equal thanks goes to Prof. Dr. Ramesh Bajracharya and Dr. Roshan Thapa.

\section{References}

Airely, D. \& Tribe, J. (2000). Education for hospitality. In Lashley, C. \& Morrison, A.(Eds.) In Search of Hospitality: Theoretical Perspectives and Debates (pp.276291), Oxford: Butterworth/Heinemann.

Ayikoru, M., Tribe, J. \& Airey, D.(2009). Reading tourism education. Neoliberalism unveiled. Annals of Tourism Research, 30(2):101-221. 
Barrows, C. W. \& Johan, N. (2008). Hospitality management education. In Brotherton, B. \& Wood, R. C. (Eds.) The Sage Handbook of Hospitality Management (pp.146162), London:Sage

Baum,T.(2006).The future of work and employment in tourism.In Buhalis, D.\& Costa,C.(Eds.) Tourism Management Dynamics Trends :management and tool. (pp.130-136),Elsevier.

Boyle, A., Wilson, E \& Dimmock, K. (2015). Space for sustainability? Sustainable education in the tourism curriculum space. In Dredge, D., Airey, D. \& Gross, J. (Eds.) The Routledge Handbook of Tourism and Hospitality Education (pp. 519532), London: Routledge

Brotherton, B. \& Wood, R. C. (2000). Defining hospitality and hospitality management In Lashley, C. \& Morrison, A. (Eds.) In Search of Hospitality: Theoretical Perspectives and Debates (pp.134-156), Oxford: Butterworth/ Heinemann.

Brotherton, B. (1999). Towards a definitive view of the nature of hospitality and hospitality management. International Journal of Contemporary Hospitality Management, 11 (4):165-173.

Brotherton, B. (2002). Finding the hospitality industry (A Response to Paul Slattery). Journal of Hospitality, Leisure, Sport and Tourism Education 2(1):75-77.

Brotherton, B. (2003). Finding the hospitality industry- A final response to Slattery? Journal of Hospitality, Leisure, Sport and Tourism Education 2(2):67-70.

Brotherton, B.(2010).Researching Hospitality and Tourism: A Student Guide, London: Sage.

Buergermeister, J., D’Amore,L.,Jafari,J.\& Pearce,D.(1992). New horizons in tourism hospitality education. Annals of Tourism Research, 19:139-142.

Caton, K. (2015). On the practical value of the liberal education. In Dredge, D., Airey, D. \& Gross, M. J. (Eds.) The Routledge Handbook of Tourism and Hospitality Education pp.(43-54), London:Routledge.

Cavlek, N.(2015). Experiential learning in tourism education: The case of ITHAS. In Sheldon, P.J. \& Hsu,C.H.C.(Eds.) Tourism Education : Global Issues and Trends (pp. 101-113), United Kingdom : Emerald .

Coles, T., Hall, C. M. \& Duval, D. T. (2006).Tourism and post-disciplinary inquiry. Current Issues in Tourism, 9 (4\&5):293-319.

Creswell, J.W.(2009).Research Design, London: Sage.

Darbellay, F. \& Stock, M. (2012). Tourism as complex interdisciplinary research object. Annals of Tourism Research, 39 (1): 441-458.

Dredge, D., Benckendorff, P., Day, M., Gross, M. J., Walo, M., Weeks, P. \& Whitelaw, P. 
A. 2012). The Philosophic practitioner and curriculum space. Annals of Tourism Research, 39 (4):2154-2176.

Echtner, C. M. (1995). Tourism education in developing nations: A three pronged approach. Tourism Recreation Research, 20(2):32-41.

Echtner, C.M \& Jamal, T. B. (1997). The disciplinary dilemma of tourism studies. Annals of Tourism Research 24(2):868-883.

Edelheim,J.R.(2015). Ontological, epistemological and axiological issues. In Dredge, D., Airey, D. \& Gross, M. J. (Eds.) The Routledge Handbook of Tourism and Hospitality Education (pp.30-42). London: Routledge.

Evans, N. (2012). Tourism: A strategic business perspective. In Jamal, T. \& Robinson, M.(Eds.) The Sage Handbook of Tourism Studies.(pp.215237),London: Sage.

Fidgeon, P.R.(2010). Tourism education and curriculum design : A time for consolidation and review. Tourism Management, 37:699-723.

Fuchs, M., Fredaman, P. \& Ioannides , D. (2015). Tourism PhD. studies: A Swedish experiences - based perspective. In Sheldon, P.J. \& Hsu, C.H.C. (eds.) Tourism Education: Global Issues and Trends (pp. 61-79), United Kingdom : Emerald.

Getz, D. (2007).Event Studies: Theory, research and policy for planned events, Amsterddam :Elsevier.

Graburn, N. H. H \& Jafari, J. (1991). Introduction. Tourism social science. Annals of Tourism Research, 18 (1): 1-11.

Grant,K.A.(Ed.) (2011). Case Studies in Knowledge Management Research, Reading : Academic Publishing International.

Gross, M. \& Lashley, C. (2015). Hospitality higher education. In Dredge, D., Airey, D. Gross, M. J. (Eds.) The Routledge Handbook of Tourism and Hospitality Education (pp.73-84), London:Routledge.

Hall, C.M., Williams, A.M. \& Lew, A.A .(2005). Tourism : Conceptualizations, institutions and issues. In Lew, A.A., Hall, C.M \& Williams, A.M. (Eds.). A Companion to Tourism (pp. 3-23), First- Indian Reprint.

Hall, M. (2004). Reflexivity and tourism research: Situating myself and/with others. In Phillimore, J. \& Goodson, L. (Eds.) Qualitative Research in Tourism: ontologies, epistemologies and methodologies (pp. 137-155), London: Routledge.

Harrison,D. (2015). Educating Tourism Students in the South Pacific. In Dredge,D., Airey,D.\&Gross,M.J.(Eds.) The Routledge Handbook of Tourism and Hospitality Education (pp.225-234). London: Routledge. 
Hein, G.E.(2006). Museum education. In Macdonald,S.(Ed.) A Companion to Museum Studies (pp.340-352),Oxford: Blackwell.

Henry,S. (1987). Disciplinary pluralism: Four models of private justice in the workplace. The Sociological Review, 35 (2): 279-319.

Higgins - Desbiolles , F. (2013) . No high hopes for hopeful tourism: A critical comment. Annals of Tourism Research, 40: 428-433.

Higgins - Desbiolles,F.(2006). More thanm an "industry": The forgotten power of tourism as a social force, Tourism Management, 27: 1192-1208.

Hoffman N.B. (2013). 'Locating' or' dislocating' heritage and cultural tourism within the humanities. TD The Journal for Transdisciplinary Research in Southern Africa, 9(2): 341-356.

Hollinshead, K. \& Evanova, M. (2004).A premier in ontological craft: The creative capture of people and places through qualitative research. In Phillimore, J. \& Goodson, L,(Eds.) Qualitative Research in Tourism: ontologies, epistemologies and methodologies (pp. 63-82), London: Routledge.

Hollinshead, K. \& Evanova, M. (2013). The multilogical imagination: Tourism studies and the imperative for postdisciplinary knowing. In Smith, M. \& Richards, G. (Eds.) The Routledge Handbook of Cultural Tourism (pp.53-62), London: Routledge.

Hsu, C. H. (2015). Tourism and hospitality education. In Dredge, D., Airey, D., \& Gross, M. J. (Eds.) The Routledge Handbook of Tourism and Hospitality Education (pp. 197-209). London: Routledge.

Innui,Y, Wheeler, D.\& Lankford, S.(2006)Rethinking Tourism education: What should school teach? International Journal of Contemporary Hospitality Management.6 (2) : 25-36.

Issac, R.(2013). Responsible tourism and development in the context of peace building. In Wohlmuther, C.A.\& Wintersteiner, W.(Eds.) International Handbook on Tourism and Peace (pp.87-100), Centre for Peace Research and Peace Education of the Kalgenfurt- Uiversity/Austria in cooperation with the world tourism Organization (UNWTO),DRAVA

Jafari, J. \& Ritchie, J.R.B.(1981). Toward a framework for tourism education: Problems and prospects. Annals of Tourism Research, 13-34.

Jafari, J. (1990). Research and scholarship: The basis fo tourism education. The Journal of Tourism Studies, 14(1): 6-16.

Jamal, T., Taillon, J. \& Dredge, D. (2011). Sustainable tourism pedagogy and academiccommunity collaboration: A progressive service-learning approach. Tourism and Hospitality Research, 11(2):133-147. 
Jauhari, V.(2006). Competencies for a career in the hospitality industry: An Indian perspective. International Journal of Contemporary Hospitality Management, $18(2): 123-134$.

Jennings, G. R. (2012). Methodologies and methods. In Jamal, T. \& Robinson, M.(Eds.). The SAGE Handbook of Tourism Studies (pp.672-692), London:Sage.

Jones, P. L (1998). Editorial. International Journal of Hospitality Management, 17: 105-110.

Kane, J. (1986). Participative management as a key to hospitality excellence. International Journal of Hospitality Management, 6(3):149-151.

Kellert, S.H.(2008). Borrowed Knowledge: Chaos Theory and The Challenge Learning Across Disciplines, Chicago: University of Chicago Press.

Ko, W-H. \& Chung, F-M. (2014). Teaching quality, learning satisfaction, and academic performance among hospitality students in Taiwan. World Journal of Education, 4(5): 11-20.

Koh,K.(1995).Designing the four year tourism management curriculum : A marketing approach. Journal of Travel Research,34 (1):68-72.

Kunwar, R. R. (2017). Tourists and Tourism: Revised and Enlarged Edition, Kathmandu: Ganga Sen Kunwar.

Kunwar, R. R. (2017). What is Hospitality? The Gaze Journal of Tourism and Hospitality, 8(1):55-115.

Kunwar,R.R(2013). Nepal Himalayan region: the living laboratory for mountaineering education and mountain tourism research. Journal of Tourism and Hospitality Education, 3: 1-31.

Leiper, N. (1981). Toward a cohesive curriculum in tourism the case for a distinct discipline. Annals of Tourism Research, 69-84.

Leiper, N. (2000). An emerging discipline. Annals of Tourism Research, 27(3):805-809.

Lewis- Cameron, A.(2015). Rethinking Caribbean tourism education. In Sheldon, P.J. \& Hsu, C.H.C.(Eds.) Tourism Education : Global Issues and Trends (pp.81-97), United Kingdom : Emerald.

Lewis,A.\& Tribe, J. (2002). Critical issues in the globalization of tourism education. Tourism Recreation Research, 27 (1): 13-20.

Liu,A.\&Wall,G.(2006).Planning tourism employment: a developing country perspective. Tourism Management ; 27:159-170.

Lusiani, M. \& Zan, L.(2013). Guest Editorial. Planning and Heritage. Journal of Cultural Heritage Management and Sustainable Development, 3(2):pp 108-115. 
Mao, H. \& Zeping, W. (2010). Tourism management professional training mode innovation. Asian Social Science. Canadian Centre of Science and Education, 6 (7) : 87-90.

Marchiori, E\&Cantoni , L.(2015). Including augmented reality in tourism education programs. In Sheldon, P.J. \& Hsu , C.H.C. (Eds). Tourism Education Global Issues and Trends (pp.115 -134), United Kingdom : Emerald.

Maureeen, A., Tribe, J. \&Airey, D. (2009).Reading tourism education neoliberalism unveiled. Annals of Tourism Research, 36(2) :191-221.

Mayaka,M.\&Akama,J.(2007).Systems approach to tourism training and education: The Kenyan case study.Tourism Management,28:298-306.

Mayaka,M.A. \& Akama,J.S.(2015).Challanges for the tourism,hospitality and events higher education curricula in Sub-Saharan Africa. In Dredge, D., Airey, D. \& Gross,M.J.(Eds.) The Routledge Handbook ofTourism and Hospitality(pp. 235249), London: Routledge.

Mayaka,M.A.\& Akama,J.S.(2015). Challenge for the tourism hospitality and events higher education curricula in Sub-Sharan Africa :The case of Kenya: In Dredge,D.,Airey,D.\& Gross,M.J.(Eds.) The Routledge Handbook of Tourism and Hospitality Education (pp.235-249), London : Routledge.

McKean, P.F.(1989). Towards a theoretical analysis of tourism : Economic dualism and cultural involution in Bali. In Smith,V.L.(Ed.) Hosts and Guests : The Anthropology of Tourism (pp.119-138), Philadelphia: University of Pennsylvania Press.

Mihalič,T. , Liburd ,J. J., \& Guia, J .(2015). Values in tourism. The case of EMTM. In Sheldon ,P.J. \& Hsu C.H .C. (Eds.)Tourism Education Global Issues and Trends (pp.41-59).United Kingdom : Emerald .

Morgan, M. (2004). From production line to Drama School: Higher education for the future. International Journal of Contemporary Hospitality Education, 16 (2): 91-99.

Morrison, A. \& O'Gorman, K. (2008).Hospitality studies and hospitality management: A symbiotic relationship, International Journal of Hospitality Management, 37:214-221.

Nigel, E. (2009). Tourism: A strategic business perspectives. In Jamal, T. \& Robinson, M. (Eds.) The Sage Handbook of Tourism Studies (pp.215-234), London:Sage.

O’Mahony, B.\& Salmon,G.(2015). The role of Open Online Courses (M00Cs) in the democratization of tourism and hospitality education. In Dredge, D., Airey, D. \& Gross,M.J.(Eds.) The Routledge Handbook ofTourism and Hospitality (pp. 130142), London: Routledge. 
Obenour,W.L.,Lengfelder,J. \& Cuneen,J.(2005) Body of knowledge for a tourism curriculum: Revisited. Schole: A journal of leisure Studies and Recreation 20: 43-56.

Phillimore, J. \& Goodson, L. (Eds.) (2004). Qualitative Research in Tourism: Ontologies, epistemologies and methodologies, London:Routledge.

Portegies , A., De Haan, T. \& Platenkamp, V. (2009). Knowledge production in tourism: The evaluation of contextual learning processes in destination studies. Tourism Analysis, 14: 523-536.

Pritchard,A.,Morgan,N.\& Ateljevic,X.(2011). Hopeful tourism: A new transformative perspective. Annals of Tourism Research,38(3):941-963.

Rachela, p. \& Hu, C. (2009). A framework for knowledge_based crisis management in the hospitality and tourism industry. Cornell Hospitality Quarterly, 50 (4): 561-577.

Rajaram, R.(2008). Human Capital, Delhi: Foundations.

Rakić, T. (2010).Tales from the field: Video and its potential for creating cultural tourism knowledge. In Richards,G. \& Munsters, W.(Eds.) Cultural Tourism Research Methods.(pp.129-140), Wallingford: Cabi.

Repko, A. F. (2012). Interdisciplinary Research Process and Theory, London:Sage.

Ritalahti,J.(2015). Inquary learning in tourism Haaga-Helia Porvoo Campus. In Sheldan,P.J.\& Hsu, C.H.C(eds.) Tourism Education Global Issues and Trends (pp.135-151), United Kingdom: Emerald.

Ritchie, B. W., Burns, P. \& Palmer, C. (Eds.) (2005). Tourism Research Methods : Integrating theory with practice, Wallingford : Cabi Publishing.

Shariq, S.Z.(1997). Knowledge management: An emerging discipline. The Journal of Knowledge Management, 1(1):75-82.

Sheldon, P. J. \& Fesenmaier, D. R. (2015).Tourism education futures initiative: current and future curriculum inferences. In Dredge, D., Airey, D. \& Gross, M. J.(Eds.) The Routledge Handbook of Tourism and Hospitality Education (155-170), London:Routledge.

Slattery, P. (2002). Finding the hospitality industry. Journal of Hospitality, Leisure, Sport and Tourism Education,1(1):19-27.

Slattery, P. (2003). Finding the hospitality industry (Slattery's Reply to Brotherton). Journal of Hospitality, Leisure, Sport and Tourism Education. 2(1): 119-120

Sogayar,R.L.\& Rejowski,M.(2015). Tourism, hospitality and events curriculum in higher education in Brazil: Reality and challenges. In Dredge,D.\& Gross, M.(Eds.) The Routledge Handbook of Tourism and Hospitality Education (pp.210224),London :Routledge. 
Su, Y. (2015). Lifelong learning in tourism education. In Dredge, D. Airey, D. \& Gross, M. J. (Eds.) The Routledge Handbook of Tourism and Hospitality Education (pp.322-334), London: Routledge.

Taylor, S. \& Edgar, D. (1996). Hospitality research: the emperor's new clothes? International Journal of Hospitality Management, 15(3): 211-227.

Terkenli, T. S. (2005). Tourism and landscape. In Lew, A. A., Hall, C. M., \& Williams, A. M. (Eds.) A Companion to Tourism (pp. 339-348). First Indian Reprint.

Tribe, J. \& Xiao, H. (2011). Developments in tourism social science. Annals of Tourism Research, 38(1):7-20.

Tribe, J. (1997). The indiscipline of tourism. Annals of Tourism Research, 24(3):682657.

Tribe, J. (2000). Indisciplined and Unsubstantiated. Annals of Tourism Research, 27(3):809-813.

Tribe, J.(2002). The philosophic practitioner. Annals of Tourism Research, 29 (2): 338357.

Tribe, J. (2004). Knowing about tourism: epistemological issues. In Phillimore, J. \& Goodson, L. (Eds.) Qualitataive Research in Tourism (pp.46-62), London:Routledge.

Tribe, J. (2006). The truth about tourism. Annals of Tourism Research, 33(2):360-381.

Tribe, J. (2008). Tourism : A critical business. Journal of Travel Research, 46:245-255.

Tribe, J. (2010). Tribes, territories of networks in the tourism academy. Annals of Tourism Research, 37(1):7-33.

Tribe, J. (2015). The curriculum: A philosophic practice? In Dredge, D., Airey, D. \& Gross, M. J. (Eds.) The Routledge Handbook of Tourism and Hospitality Education (pp.17-29), London: Roultedge.

Tzortzaki, A.M.,Mihiotis, A.\& Agiomiragianakis , G.M.(2011) The quest for a new multidisciplinary tourism model. Annals of Tourism Research, 38 (1):325-330.

Volgger, M. \& Pechlanner, H. (2015). Interdisciplinarity, transdisciplinarity and postdisciplinarity in tourism and hospitality education. In Dredge, D., Airey, D. \& Gross, M. J. (Eds.) The Routledge Handbook of Tourism and Hospitality Education (pp.85-1023), London: Routledge.

Weiler, B., Moyle, B. \& McLenannan, C.(2012). Discipline that influence tourism Doctoral research in the United States, Canada, Australia and New Zealand, Annals of Tourism Research, 39:1425-1445. 
Zaei, M. E., \& Zaei, M. E. (2014). Knowledge management in hospitality and tourism industry: A KM research perspective. Information and Knowledge Management, 4(9): 114-122.

Zeglat,D.\& Zigan,K.(2014). Intellectual capital and its impact on business performance: Evidences from Jordanian hotel industry. Tourism and Hospitality Research, 13(2): 83-100. 